\title{
La mediación comunicativa y la construcción de identidades: El Nacionalismo en Québec
}

Un análisis del discurso en grupos de discusión que debaten sobre comunicación en los Medios desde su identidad nacional

\author{
José Luis Piñuel Raigada \\ Departamento de Sociología IV \\ U.C.M.
}

\section{INTRODUCCIÓN}

El estudio de la representación social del nacionalismo, precisamente cuando nos encontramos en el momento histórico en que el proceso de globalización se extiende por doquier, constituye un desafío científico si se quiere comprender cómo la mediación comunicativa (Piñuel y Gaitán, 1995; Piñuel, 1997) resulta a su vez mediatizada por la conciencia de la historia local de cada comunidad.

Se pueden plantear problemas sobre cómo la comunicación interviene como instancia mediadora en la construcción de identidades colectivas (Piñuel, 1986, Piñuel 1987, Piñuel 1993, Piñuel y Gaitán 1995, etc.), y una forma frecuente para tratar de resolverlos consiste en utilizar la metodología del análisis de contenido para estudiar el flujo comunicativo que circula a través de los Medias.

Pero otra aproximación prometedora de jugosos resultados es estudiar el discurso que se produce en grupos de discusión cuando en ellos se debate, por ejemplo, la información periodística de la actualidad. Pero para llegar a distinguir con alguna precisión a través del análisis, lo que procede de los relatos mediáticos, y lo que aportan los esquemas cognitivos previamente disponibles en la mente de los sujetos para poder construir el sentido del discurso grupal, debe elegirse un objeto de estudio que permita:

- Delimitar el universo de referencia de los productos mediáticos susceptibles de provocar la discusión del grupo.

- Delimitar el universo de referencia de los esquemas cognitivos disponibles en el grupo para construir el sentido del discurso grupal.

- Delimitar el universo de referencia susceptible de facilitar, tanto la selección de los participantes, como la comparación intercultural. 
Un objeto de estudio que puede facilitar todo esto es el NACIONALISMO, ya que se trata de un universo de referencia a menudo presente en el flujo mediático, pero sobre todo porque el universo de referencia del NACIONALISMO contiene siempre un capital muy rico en esquemas cognitivos colectivamente compartidos e interculturalmente comparables.

Con tales presupuestos, esta investigación aborda el estudio de la representación colectiva de un nacionalismo que, además, supuestamente es diferente de aquellos otros fuertemente contaminados por las tensiones cosmogónicas excluyentes que derivan de la violencia terrorista, pero que, sin embargo, no renuncia a aspiraciones de independencia política. La elección, metodológicamente estratégica, de estudiar el nacionalismo de Québec, permite por otra parte proseguir con estudios posteriores susceptibles de abordar comparaciones interculturales.

\section{EL ESTUDIO DE LA REPRESENTACIÓN SOCIAL DEL NACIONALISMO}

Precisamente cuando nos encontramos en el momento histórico en que el proceso de globalización se extiende por doquier, el estudio de la representación social del nacionalismo constituye un desafío científico si se quiere comprender cómo la mediación comunicativa (Piñuel y Gaitán, 1995, Piñuel, 1997) resulta a su vez mediatizada por la conciencia de la historia local de cada comunidad.

En efecto, es de todos conocido cómo las tensiones políticas, sociales, económicas y culturales que acompañan al proceso ya universalmente denominado de la Globalización, han sido a su vez generadas y reproducidas por la implantación de las tecnologías vinculadas a la Comunicación (Castells, 1998). No debiera tampoco pasarse por alto que, si bien las tecnologías vinculadas a la Comunicación afectan a las condiciones en que la comunicación global se produce, su implantación no ha sido consecuencia de la decisión por mejorar las comunicaciones (liberándolas de resistencias fisico-temporales), sino de mejorar la gestión de la producción capitalista mediante la implantación cada vez más rentable de la tecnología comunicativa. En este sentido, no ha habido cambio: la comunicación subsidiariamente se mejora para hacer más rentable la producción, y no a la inversa, como sería el caso de que, persiguiendo mejorar la producción, se consiguiese hacer más libre la comunicación a costa de gastos en la producción. El cambio, sin embargo, en las infraestructuras comunicativas que llevan a las tensiones políticas, sociales, económicas y culturales que acompañan al proceso ya universalmente denominado de la Globalización requiere no sólo incrementos de gasto productivo, sino también transformaciones de los esquemas cognitivos disponibles para que la comunicación global sea posible. Por ejemplo, es obvio que globalización y nacionalismo parecen nociones contrapuestas hasta el punto de que la defensa de una implicaría la negación de la otra, y sin embargo es la práctica de la comunicación la que las hace compatibles e incluso complementarias. En este sentido, cabría preguntarse si se han transformado los esquemas cognitivos disponibles sobre el nacionalismo para que la comunicación global sea posible, habida cuenta del supuesto de que todo nacionalismo hunde sus raíces en la 
historia de las comunidades locales (tensión centrípeta), mientras que la globalización desborda cualquier localismo apuntando hacia afuera (tensión centrífuga). Estudiar cómo la práctica de la comunicación media en este conflicto requiere también hacer explícitas las condiciones teóricas en virtud de las cuales puede estudiarse el cambio de los esquemas de conocimiento por la mediación de la praxis comunicativa, y viceversa, cómo los esquemas de conocimiento afectan al cambio de la comunicación.

\section{A) La dialéctica praxis interaccional y esquemas de conocimiento}

Los actores de una interacción comunicativa no se enfrentan normalmente por primera vez a la tarea de comunicarse con otro ser humano. Poseen, en este sentido, un determinado conocimiento acerca de las posibilidades expresivas del cuerpo humano, acerca de la significatividad de ciertas expresiones y acerca de las pautas de acción y coordinación de acciones y operaciones que regulan esta clase de interacciones comunicativas. El «saber hacer» acerca de la comunicación es un patrimonio cognitivo, es decir, es un producto de la práctica comunicativa, que se almacena en la memoria de los sujetos y que se activa cuando estos entran a tomar parte de una interacción comunicacional en forma de «esquemas previos» («auto-referencia, que guían la construcción recursiva de nuestras «representaciones e inferencias» (Piñel y G. Lomas, 2001). Los esquemas que poseemos acerca de los demás (esquemas sociales), contienen datos que no sólo se refieren a las propiedades identitarias del sujeto (su edad, su sexo, su aspecto físico, su personalidad, su familiaridad -si es conocido o desconocido- su nivel de conocimientos, etc.), sino también a la posición que ocupan (status) y a la función que desempeñan (rol) dentro de los grupos y organizaciones sociales, es decir, en su calidad de agentes de un sistema social. Esos datos pueden hacer que nos comportemos de una u otra manera. Por ejemplo, no nos comportamos de la misma manera con un dependiente de un comercio al que acabamos de conocer (del que esperamos que cumpla ciertas funciones y se comporte de acuerdo a su rol), que como nos comportamos con un amigo de toda la vida, ni tampoco esperamos que ellos se comporten de la misma manera.

En otros lugares he desarrollado con muy distintas aplicaciones un modelo teórico 2 que prefigura estas diferentes dimensiones (comunicativas, identitarias

\footnotetext{
2 Se trata del modelo de la MDCS (Mediación Dialéctica de la Comunicación Social) el cual formula un sistema conceptual especializado en la descripción, explicación y predicción de los cambios históricos que experimentan o pueden experimentar los sistemas de comunicación propios de nuestras sociedades. Entre sus principales postulados o hipótesis de base, se encuentra la idea de que dichos cambios no pueden conocerse si no se establece primero una clara diferenciación entre los componentes y relaciones que son específicos de los sistemas de comunicación (SC) y los componentes y relaciones que son específicos de otros sistemas. Una vez efectuada esa diferenciación, el modelo postula que los cambios históricos de los sistemas de comunicación (SC) sólo pueden explicarse examinando las relaciones de apertura que dicho sistema mantiene con otros dos sistemas generales: el sistema social (SS) y el sistema ecológico-adaptativo (SE), cuyo específico inventario de componentes genéricos y de relaciones internas (estructurales y funcionales) es igualmente proporcionado por dicho modelo (Cfr. Martín Serrano, M., 1981, 1989, pero especialmente
} 
y sociales) las cuales se encuentran analíticamente separadas porque tal operación formal es epistemológicamente rentable para encontrar una explicación científica de los cambios históricos de la sociedad, el conocimiento y la cultura. Sin embargo en el funcionamiento normal de nuestro sistema cognitivo, no existen tres procesadores modulares diferentes: los datos de tipo identitario, social y comunicacional, cuando se refieren a nuestros congéneres, forman estructuras unitarias de conocimiento que han recibido el nombre en Psicología Cognitiva de «esquemas sociales».

Los «esquemas», en tanto que estructuras de conocimiento, son estructuras de categorías o variables de naturaleza «difusa», es decir, sin limites exactos y absolutos, cuya relación estructural impone una cierta covariación a los valores de cada una de las variables o categorías que constituyen específicamente un esquema determinado, dentro de un amplio y flexible umbral de valores posibles. Así, nuestro esquema de «hotel», por ejemplo, puede arrojar múltiples representaciones o variantes concretas, pero al variar uno de los constituyentes tienden a covariar los valores restantes. Por ejemplo, un hotel de lujo y una pensión barata tienen en común ciertas variables como es el hecho de tener habitaciones y tener un precio. Al variar el precio hacia la baja, las calidades de la habitación también «bajan». Ciertamente, existirá un límite hacia la baja y otro hacia la alta, pero el umbral es amplio y es históricamente flexible. Lo interesante en este sentido es que existe una tendencia hacia la covariación, y por tanto es difícil encontrar pensiones baratas con calidades y servicios de lujo, como es difícil encontrar hoteles carísimos con calidades y servicios extraordinariamente «bajos». En el centro podemos obtener sin embargo hoteles relativamente baratos con servicios y calidades buenos, o pensiones relativamente caras con servicios y calidades relativamente bajos, etc. Similarmente podríamos razonar para muchos de nuestros esquemas identitarios: el esquema de «catalán», o el esquema de «vasco», o de «español», etc. ofrecen múltiples representaciones o variantes concretas («el

Piñuel, J.L. 1989, y Piñuel J.L. y Gaitán, J.A, 1995). La concepción de los sistemas de comunicación (SC), de los sistemas sociales (SS) y de los sistemas ecológi-coadaptativos (SE) como sistemas abiertos entre sí, nos permite describir la transformación histórica de cada uno de esos tres sistemas en términos de una mediación dialéctica «intersistémica», es decir, concibiendo la transformación interna de un determinado sistema como el producto histórico de la influencia externa que ejercen sobre él los sistemas restantes y viceversa. De esta manera, los cambios en los sistemas de comunicación (SC) se describen normalmente identificando, en primer lugar, al menos dos estados del sistema de comunicación (correspondientes a dos momentos históricos diferentes), para una vez comparados y señaladas sus transformaciones, analizar entonces el valor que puede tener el análisis de la influencia ejercida en y/o por el sistema social (SS) y la influencia ejercida en y/o por el sistema ecológico-adaptativo (SE) como factores explicativos del cambio experimentado por el sistema de comunicación (SC). Si consideramos ahora las estructuras y condiciones del conocimiento humano como componentes del sistema ecológico-adaptativo (sistema que regula, por definición, las relaciones entre el organismo humano y su entorno), será fácil comprender que el modelo de la MDCS contiene implícitamente una cierta teoría acerca del cambio histórico de dichas estructuras y algoritmos. Desde esa teoría implícita el cambio histórico del sistema ecológico-adaptativo (SE) podría igualmente conocerse (describirse, explicarse o predecirse) examinando el papel que juegan los sistemas de comunicación, SC, y los sistemas sociales, SS, en su transformación interna, y viceversa: examinado a su vez el papel que juega el propio sistema ecológico-adaptativo (SE) en la transformación de los otros dos sistemas. 
industrial catalán», vs. «el payés catalán»; o el «industrial vasco» vs. «el paisano de los caseríos»; etc.) e imponen una cierta covariación: al variar uno de los constituyentes tienden a covariar los valores restantes.

Las meta-representaciones que construimos puntualmente acerca de nuestro interlocutor, en cada proceso comunicativo, se encuentran guiadas por los conocimientos sociales previos, por nuestros «esquemas sociales». Los esquemas activados y las meta-representaciones referidas a las intenciones, creencias y estados mentales de nuestro interlocutor (teorías de la mente), juegan un papel fundamental en la regulación de nuestra propia conducta, pues anticipan una expectativa acerca de los límites específicos de esa interacción, o para decirlo con otros términos: colaboran en la formación del sentido mismo de la interacción. Lógicamente si los esquemas sociales que activamos se corresponden a la realidad, es decir, si el sujeto que tenemos enfrente se comporta dentro del margen de variables previstas, entonces las posibilidades de acoplamiento interactivo de nuestras acciones son mayores. Pero para que el acoplamiento interactivo sea completo, también la otra persona (alter), debe activar esquemas sociales y metarepresentaciones acerca de nosotros mismos y de nuestro comportamiento, que le permitan formar una expectativa que efectivamente se ajuste a la realidad. Ahora bien, también es posible «falsificar» el comportamiento y asumir un «esquema social» que no se adecua con el que realmente nos corresponde, como es igualmente posible «confundirse» y atribuir a los demás una identidad social (activar un esquema social inadecuado) que no es el que se ajusta a la realidad.

Tanto si se consideran situaciones interpersonales de interacción, del tipo de encuentros sociales «cara a cara» para los que siempre podríamos encontrar guiones (como por ejemplo el encuentro social entre un vendedor y el cliente en unos almacenes -donde dominan patrones sociales-, o el encuentro sexual -donde dominan patrones afectivos y eróticos-, etc.), que son propios de una perspectiva «microsociológica», como si aumentamos la escala y asumimos una perspectiva macrosociológica, es evidente que no podemos penetrar con el mismo detalle o granularidad en los esquemas y meta-representaciones individuales, y que tendremos que utilizar algún método que permita describir el patrimonio social y no ya meramente individual de esquemas cognitivos previos o disponibles.

Para describir ese patrimonio cognitivo es necesario recurrir, a mi entender, a un nuevo concepto: el concepto de «socio-esquema» (Piñuel y G-Lomas, 2001). Este concepto es una síntesis emergente entre el concepto de «modelos de representación» y el concepto de «esquema cognitivo». Por esta razón, en el concepto sintético de «socio-esquema» se salva la idea de «modelo» en el sentido de que podemos descubrir los límites de los «esquemas» cognitivos disponibles para un grupo social, pero los datos de base no serán obtenidos a partir del análisis de los relatos de los mass media ${ }^{3}$, sino a partir de los discursos que los sujetos constru-

${ }^{3}$ Los agrupamientos lógico-categoriales que subyacen, por ejemplo, a una muestra representativa de relatos (de prensa, de radio, de TV, publicitarios, informativos, de entretenimiento, etc) hacen referencia a los límites hipotéticos de las representaciones individuales que pueden construirse por sujetos «competentes» a la hora de procesar dichos relatos. Las representaciones cognitivas individuales han sido hasta ahora consideradas impenetrables o inescrutables, pero se suponía que sus límites lógico-categoriales podían conocerse de esta forma, siendo que cada muestra de relatos refle- 
yen al encontrarse experimentalmente sometidos a la tarea de discutir y conversar construyendo grupalmente un acuerdo acerca de su conocimiento previo y de sus representaciones sobre los mass media y sus relatos, de forma que el acuerdo que los sujetos construyen deja de ser contingente y se torna en transcendente (Ibañez, 1986), es decir común al grupo y a una comunidad, pues este mismo discurso no tendría sentido sin grupo, sin comunidad y sin discusión.

\section{B) Los socio-esquemas identitarios y la metodología del grupo de discusión (GD)}

Los Grupos de Discusión (GD) se presentan como una técnica cualitativa de reunión de grupo que permite obtener un conocimiento aproximativo de la realidad social que se pretende investigar, mediante la comunicación que se produce en su seno. El GD viene a conformarse entonces como una representación micro (subgrupo) de una macrosituación social. Su composición se estructura en orden a reproducir, de forma paradigmática, determinadas relaciones sociales que interesa conocer dada una perspectiva investigadora y un tema o problema objeto de estudio: en nuestro caso, la identidad nacional, y más concretamente el nacionalismo de Québec que los propios nacionalistas de diversa índole expresan ${ }^{4}$.

Del GD, siendo un grupo artificial, creado como un precipitado social, interesan tanto sus resultados como su desarrollo, pues en él se resume, como grupo posible, una porción de vida social en condiciones de control cuasi-experimenta-

\footnotetext{
ja indirectamente dichos límites. El análisis de los modelos lógico-categoriales subyacentes a los productos narrativos que se difunden por los mass media nos pondría, desde esta perspectiva metodológica, sobre la pista de los límites que en ese momento de la historia presentan las representaciones individuales inducidas por la propia constricción lógico-semántica y referencial de los relatos. Ese concepto, sin embargo, lleva a los investigadores a buscar los «modelos de representación» en los textos, y no en la mente de los receptores. En ese sentido, la propia metodología -más próxima a un análisis de contenido, que a un análisis de representaciones cognitivas propiamente dicho- convierte entonces al «analista» en sujeto cualificado y competente para la «interpretación». A los analistas se les proporciona entonces un panel de instrucciones comunes, con sus respectivas variables y categorías e inventario de relaciones lógicas (atributos excluyentes, solidarios, condicionales, etc). $\mathrm{Al}$ leer o interpretar los textos, deben ir rellenando las casillas categoriales previstas en una determinada matriz de variables analíticas y examinar su asociación efectiva en el relato (frecuencia aislada, frecuencia de asociaciones, etc). Aplicando la misma matriz a muestras diferentes de relatos (por ejemplo, a muestras de relatos producidos en momentos históricos diferentes), se obtiene un diferencial histórico que se predica respecto de los «modelos de representación» subyacentes. Sin embargo, al ignorar el papel de los esquemas cognitivos previos en los procesos reales de comprensión, se obvia o se olvida el fenómeno de la «comprensión aberrante», o si se prefiere, de la comprensión «real». Efectivamente la comprensión real puede tener otros límites no previstos ya que los analistas no disponen de esquemas atípicos, la propia selección de categorías y relaciones introduce una constricción que no posee valencia psicológica, etc. Si se obvian o se ignoran los esquemas previos disponibles para cada individuo o grupo de individuos, se corre el riesgo de estar adjudicando el modelo de representación a la audiencia en general, cuando en realidad, dichos límites corresponden sólo al grupo representado por los analistas «cualificados».

${ }^{4}$ Las razones por las cuales se ha iniciado este estudio eligiendo el nacionalismo en Québec, se argumentarán en el apartado siguiente.
} 
les. El GD posibilita captar, ante un tema o problema planteado, determinadas necesidades, intereses y preocupaciones individuales y colectivos, así como motivaciones y actitudes, percepciones y sentimientos, creencias y opiniones suscitados en su decurso, que de otra manera permanecerían inéditos. Por ello, cada GD es único e insustituible. Ahora bien, precisamente por constituirse en grupo singular e irrepetible -aún cuando debe su formación a criterios de pertinencia-, el GD no puede ser una fuente de datos cuantitativos, pero sí de datos cualitativos extrapolables a la comunidad con la que se identifican los indivíduos del grupo, y sin cuya existencia y cultura previas la discusión del grupo carecería de sentido. En último término, el GD puede, por sí mismo, configurarse en objeto de estudio, en tanto que dinámica grupal generada por un proceso comunicacional en el cual se reproduce el discurso social inconsciente, objeto de análisis sociológico (socioanálisis, según Ibáñez, 1986).

Aunque existen diversas aproximaciones metodológicas, considerando la tecnología aplicada en los GD, cabe reconocer dos modalidades principales:

a) El GD como entrevista de grupo (el GD-EG) o «entrevista focalizada» (focus groups, focused interview)

b) El GD como socioanálisis conversacional (el GD-SC).

Ambos tipos responden a tradiciones distintas en el ámbito de las técnicas cualitativas. El GD-EG, de origen y tradición en el ámbito anglosajon (Merton, Fiske, Kendall, 1956), es el más extendido. El GD-SC, de origen español (Ibáñez, 1979, 1986), se circunscribe al área hispanohablante. Las diferencias entre estas modalidades de GD pueden apreciarse en la siguiente tabla resumen (Gaitán y Piñuel, 1997):

\begin{tabular}{|c|c|c|}
\hline & Grupes de enfoque & Socioanálesis \\
\hline $\begin{array}{l}\text { Composidion } \\
\text { de los } \\
\text { grupos }\end{array}$ & 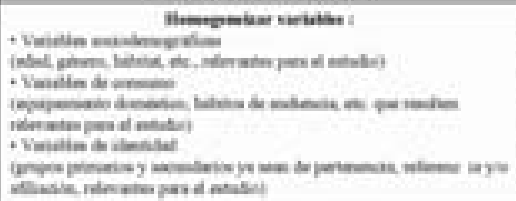 & 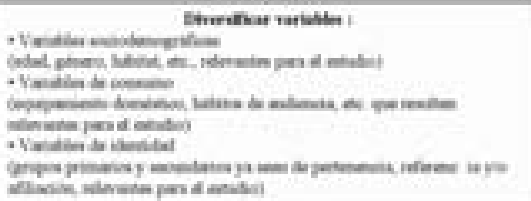 \\
\hline $\begin{array}{l}\text { Desarroblo } \\
\text { (proceso de } \\
\text { discusibn) }\end{array}$ & 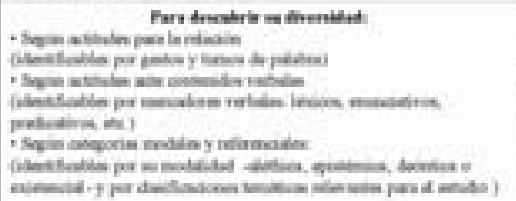 & 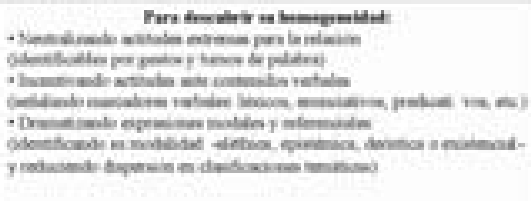 \\
\hline $\begin{array}{l}\text { Andilous ded } \\
\text { discuns }\end{array}$ & 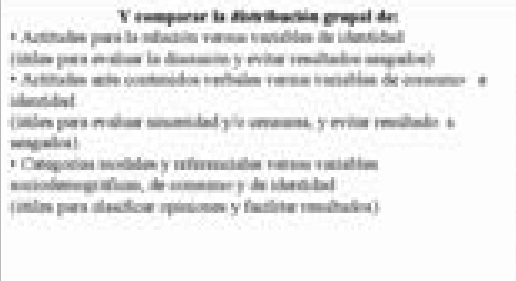 & 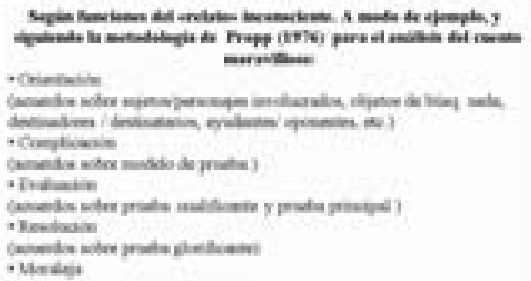 \\
\hline
\end{tabular}


En la experiencia que aquí se relata, la técnica adoptada ha sido la del socioanálisis. El paralelismo entre socioanálisis y psicoanálisis es operativo a muchos niveles. Por ejemplo, cabe de hecho encontrar un paralelismo con el psicoanálisis en lo que atañe a la actitud del mantenedor o animador de la discusión en grupo, semejante a la actitud de la «atención libre flotante» característica del psicoanalista ante su paciente, pues debe abstenerse de adoptar ante el paciente una posición crítica, selectiva o parcial y de proyectar sus propias predisposiciones y prejuicios. Algunos pasajes de Canales y Peinado (1994, p.309) ilustran de forma inmejorable el papel del mantenedor y su incidencia en el desarrollo del GD en la modalidad de lo que hemos denominado socioanálisis conversacional:

«1. Al presciptor se le pide (por parte de los actuantes) que dirija la conversación, que formule preguntas o que imponga un turno si nadie se atreve a tomar la palabra. Pero aquél rehusa la dirección formal y explícita de la discusión (...)

2. Si hay silencio será el grupo el que se angustie; y para romper la angustia habrá de tomar la palabra (...). Lo razonable (para el prescriptor) no es callar, sino insistir en que el grupo tome la palabra (...).

3. Si quien toma la palabra se dirige al prescriptor, éste no corresponderá a la demanda (...). Si pide (al prescriptor) verificación (sobre lo verdadero o falso de lo dicho) (...) el prescriptor no lo verificará, sino que devolverá la pregunta al grupo, para que sea éste el que juzgue sobre su pertinencia estructural.

4. A partir de este momento, cada miembro del grupo girará hacia el centro. Las hablas individuales tomarán como centro el propio grupo. Las diversas opiniones se verificarán y recuperarán en ese espacio. El grupo comienza a caminar al cerrarse sobre sí mismo.»

5. (...) El yo es grupal (...), pero se da como yo individual. Por ello querrá, a la vez, reconocerse en el grupo y afirmarse como entidad individual (...).»

Con esta técnica del socioanálisis conversacional se proyectó este estudio del socioesquema nacionalista de Quebec, respetando todos los extremos que pueden consultarse en los manuales en vigor, relativos tanto a la constitución de los grupos (actuantes, tamaño y números de los grupos, etc.), como a las diferentes fases de la dinámica grupal, (y que se explicitarán más adelante).

\section{C) ¿Por qué el nacionalismo de Québec?}

A la hora de ser planteada esta investigación sobre la mediación social de la Comunicación de Masas en la construcción de las identidades colectivas, estudiadas mediante la técnica del socioanálisis, y no mediante el análisis de contenido de los relatos mediáticos, debía elegirse un objeto de estudio que permitiese: 
- Delimitar el universo de referencia de los productos mediáticos susceptibles de provocar la discusión del grupo.

- Delimitar el universo de referencia de los esquemas cognitivos disponibles en el grupo para construir el sentido del discurso grupal.

- Delimitar el universo de referencia susceptible de facilitar, tanto la selección de los participantes, como la comparación intercultural.

El NACIONALISMO podía ser el objeto de estudio que facilitase el cumplimiento de tales condiciones, ya que se trata de un universo de referencia a menudo presente en el flujo mediático, pero sobre todo porque el universo de referencia del NACIONALISMO contiene siempre un capital muy rico en esquemas cognitivos colectivamente compartidos e interculturalmente comparables.

En efecto, el NACIONALISMO es un tema recurrente en los Medios, como ha sido probado en numerosos estudios, desde los pioneros de la década de 1920 y 1930, con los análisis sobre el concepto de «estereotipo social» sugerido por Lippmann (1922) y sobre el concepto de «actitud», como durante la Segunda Guerra Mundial, con los análisis de Lasswell y colaboradores., sistematizados más tarde por George (1959), Pool (1959), Lasswell y alt.(1965) y Holsti (1969).

Ahora bien, dispuestos a desvelar mediante el socioanálisis cómo pueden ser interpretados discursos mediáticos tan recurrentes, habría que diseñar la constitución de grupos de discusión integrados por individuos que dispusieran de un capital muy rico en esquemas cognitivos colectivamente compartidos e interculturalmente comparables a propósito de este mismo tema de estudio: el NACIONALISMO.

El panorama de los nacionalismos en el mundo actual es realmente muy complejo. Puede sostenerse no obstante que conviene referirse a NACIONALISMO sólo cuando se cumplen estas condiciones:

a) La referencia a una identidad colectiva que incluye a unos sujetos y excluye a otros se enmarca en relación a un tiempo y un espacio histórico: es decir, remite temporalmente a un origen que se remonta a indeterminables generaciones y se circunscribe a un territorio cuyas formas de apropiación y explotación son protegidas por leyes cuya legitimidad se dirime mediante el recurso a la fuerza políticamente organizada (Estado).

b) La referencia a una identidad colectiva que incluye a unos sujetos y excluye a otros se reviste de manifestaciones culturales en la educación, el arte, las celebraciones, etc. que sirven para reproducir mediante códigos normativos, signos externos de la diferencia frente a las identidades colectivas que han sido su matriz histórica, aun cuando compartan con ellas lengua, creencias religiosas, forma de gobierno, etc.

c) La referencia a una identidad colectiva que incluye a unos sujetos y excluye a otros se reclama como categoría que transciende a toda contingencia individual (de sexo, de edad, de dotación física o intelectual, etc.), grupal (de hábitat, recursos materiales, profesiones, etc.), y social (de clase, de opción política o religiosa, de compromisos institucionales, 
etc.) que se proyecta hacia la permanencia en el tiempo (futuro) y en el espacio (territorio) aún a riesgo de sacrificio personal.

En consecuencia, quedarían excluidos de ser considerados como nacionalismos aquellas referencias a identidades colectivas como los localismos geográficos, pues carecen de la remisión a un tiempo y a un territorio históricos, ya sea porque sus orígenes son desconocidos o nebulosos (no se han institucionalizado en la memoria colectiva), o porque jamás han dispuesto de leyes para proteger las formas de apropiación y explotación del territorio sirviéndose de una legitimidad dirimida mediante el recurso a la fuerza políticamente organizada (Estado).

Igualmente quedarían excluidos de ser considerados como nacionalismos aquellas referencias a identidades colectivas basadas en las diferencias de género sexual, raza, clan, práctica religiosa, clase social o tradiciones culturales, pues carecen de la capacidad para imponer códigos normativos en el uso de la lengua (por ejemplo, la norma culta), en las manifestaciones artísticas (por ejemplo, el folklore), o en las celebraciones (por ejemplo, los protocolos rituales o el calendario festivo). Pero sobre todo porque los signos externos de la diferencia se establecen frente a otras identidades colectivas del mismo nivel o rango, sin reconocer en ellas un origen común.

Finalmente, quedarían excluidos de ser considerados como nacionalismos aquellas referencias a identidades colectivas como los fundamentalismos étnicos o religiosos, pues aunque acepten el riesgo personal, proyectan su permanencia en el tiempo (futuro) o en el espacio (territorio) pegados a las contingencias individuales, grupales y sociales marcadas por el cumplimiento riguroso de unas prácticas exigidas de las que efectivamente depende el mantenimiento de su continuidad.

Una forma que permite comprobar cómo surgen y se establecen los nacionalismos susceptibles de cumplir con los requisitos mencionados, es estudiar su génesis y su establecimiento histórico. Así lo ha hecho Gérard Bouchard (2001) estudiando la génesis de las naciones y culturas del Nuevo Mundo. Acudiendo a la historia comparada de cómo se formaron las nuevas naciones (o culturas fundadoras) en América del Norte, América Latina, Australia o Nueva Zelanda, repasando sus itinerarios colectivos, sus modelos y modos de apropiación simbólica y cómo fue la formación de sus culturas nacionales, Bouchard ilustra magistralmente cómo las tensiones de la ruptura y la continuidad frente a las metrópolis coloniales, con sus estrategias de desgajamiento cultural, sus forcejeos por establecer una identidad nacional contrariando su diversidad interna, etc., remiten discursivamente a un origen que tiende a remontarse a indeterminables generaciones (a veces incluyendo a las poblaciones autóctonas, por ej. caso de México) y circunscribiéndose siempre a un territorio para cuyas formas de apropiación y explotación, establecieron leyes cuya legitimidad se dirimió tras el recurso a la fuerza políticamente organizada marcando su independencia (nuevos Estados).

En todos los itinerarios estudiados por Bouchard, la referencia a una identidad colectiva se revistió de manifestaciones culturales en la educación, el arte, las celebraciones, etc. que sirvieron para reproducir mediante códigos normativos, signos externos de la diferencia frente a las identidades colectivas que fueron su matriz histórica, aun cuando compartiesen con ellas lengua, creencias religiosas, e incluso en algunos casos forma de gobierno. 
Finalmente en todos los casos, aunque con diferentes itinerarios y trampas del discurso, la referencia a su identidad colectiva (los estadounidenses, los canadienses, los iberoamericanos de cada país del Nuevo Continente, los australianos o los neozelandeses), ha sido reclamada como categoría que transciende a toda contingencia individual (de sexo, de edad, de dotación física o intelectual, etc.), grupal (de hábitat, recursos materiales, profesiones, etc.), y social (de clase, de opción política o religiosa, de compromisos institucionales, etc.) y que se proyecta hacia la permanencia en el tiempo (futuro) y en el espacio (territorio) aún a riesgo de sacrificio personal.

Con un ejercicio similar al efectuado por Bouchard podría rastrearse la génesis y el decurso histórico de los nacionalismos del Viejo Continente; pero el empeño, además de ser titánico, comportaría una insalvable dificultad: los itinerarios llegarían a resultar difícilmente comparables, pero sobre todo ¿cómo marcar hitos históricos para su comparación? Si nos limitásemos a Europa Occidental, ¿podría tomarse como punto de partida el Imperio Romano? Y ¿por qué? Más de la mitad de la Europa Occidental, por ejemplo, contiene nacionalismos cuya lengua ni siquiera es románica y en sus referencias al origen histórico y territorial las disparidades difícilmente podrían resistir modelos consistentes. Por ejemplo, si partimos de los nacionalismos circunscritos a los territorios que hoy son un Estado, resultaría que Italia, cuyos vestigios culturales se remontan tan lejos, apenas habría estrenado su territorio como seña de identidad. Posiblemente todas estas circunstancias son la causa de la heterogeneidad histórica en la génesis y en el decurso de las referencias a las identidades nacionales en el Viejo Mundo, y haga de éstas un fenómeno cuya única característica común es el proceso de cambio permanente y/o de contraste histórico, dada la disparidad con que cada identidad nacional cuenta su propio tiempo: es como si cada una de ellas dispusiese de un reloj diferente en el que los segundos, los minutos y las horas se sucediesen en intervalos desiguales. Tal es así, que al interior de buena parte de los actuales Estados-nación en la Europa Occidental han aparecido durante el siglo XIX y XX movimientos nacionalistas que reclaman su propia identidad en conflicto con las identidades nacionales cuyo territorio es abarcado por el Estado. Estos conflictos, como en los casos de Irlanda del Norte frente al Reino Unido, o el País Vasco (Euzcadi) frente a España y Francia, incluso han reclamado por la fuerza, a través de sus militantes más violentos, la independencia política del territorio. De hecho, podría afirmarse que se trata de nacionalismos en formación, pues muchos de ellos jamás han dispuesto de leyes para proteger las formas de apropiación y explotación del territorio sirviéndose de una legitimidad dirimida mediante el recurso a la fuerza políticamente organizada (Estado); por esto, si su referencia al origen suele revestirse de mitos, es porque, hasta donde pueden llegar, sus manifestaciones culturales en la educación, el arte, las celebraciones, etc. aspiran a crear códigos normativos como signos externos de la diferencia vinculada a un origen que le sea privativo, frente a las identidades colectivas que han sido su matriz histórica inmediata. En fin, su apelación al futuro y al territorio llega a poner en juego un riesgo personal que, más que defender la permanencia, se torna en una conquista por la que merece la pena luchar. 
Supuestos estos planteamientos para discernir de alguna manera las características de los nacionalismos, ¿por qué nacionalismo empezar? ¿Mejor estudiar un nacionalismo del Nuevo Mundo, o del Viejo Mundo? ¿Un nacionalismo acordado en su identidad a las señas de un territorio propio políticamente gestionado por un Estado, o un nacionalismo acordado en su identidad a las señas de un territorio todavía no gestionado como un Estado independiente? Y ¿por qué no elegir un nacionalismo que, ajustándose a las características señaladas por Bouchard (2001) para las culturas fundadoras del Nuevo Mundo, comparta no obstante características propias de los nacionalismos en formación del Viejo Mundo: desgajarse política y culturalmente de la identidad colectiva que ha sido su matriz histórica inmediata para apoyarse en signos externos de la diferencia vinculada a un origen que le sea privativo? Un nacionalismo como el de Québec presenta en este sentido rasgos históricos paradigmáticos:

1. Ha participado, como todos los nacionalismos de las culturas fundadoras del Nuevo Mundo, de las tensiones entre ruptura y continuidad (Bouchard, 2001) frente a las metrópolis coloniales, con sus estrategias de desgajamiento cultural, sus forcejeos por establecer una identidad nacional contrariando su diversidad interna, etc.

2. Remite discursivamente a un origen que tiende a remontarse a indeterminables generaciones (desde los pioneros colonizadores franceses) circunscribiéndose siempre a un territorio para cuya legitimidad en las formas de apropiación y explotación, tuvo que dirimir sucesivas peripecias recurriendo a la fuerza y a la lucha política para marcar su independencia:

- Avatares de la Nouvelle France (1608-1763) resueltos con la derrota conocida como «la defaite des plaines d'Abraham» que marca el primer rompimiento, aunque para Québec, reducido al cambio de metrópoli: Gran Bretaña.

- Sucesivas tentativas (hasta 1867) de rompimiento escalonado frente a nuevas metrópolis, hasta constituirse en nación junto a sus nuevos partenaires: los angloparlantes canadienses. Optando por la fórmula del Acta de la América del Norte Británico (la AANB), se despegan tanto de los Estados Unidos protegidos por su referencia al Imperio Británico (Comunidad de Naciones), como de la propia Gran Bretaña, al verse reconocidos como Estado (Dominiom), aunque con serias limitaciones, entre ellas enmendar su Constitución sin permiso de Gran Bretaña, cuyo soberano sigue todavía siendo hoy el jefe del Estado representado por un Gobernador General.

- Entre 1867 y 1965, año en que definitivamente se adopta un himno nacional y una bandera enteramente canadiense, el nacionalismo de Québec, además, tiene que fajarse en dos frentes, uno interior y otro hacia el exterior. El interior por hacerse valer ante las prerrogativas superiores de los canadienses británicos (por ejemplo, hasta estos años sesenta no se reforma la Ley de Inmigración, expurgándola de las disposiciones preferenciales en favor de los británicos) y en general por afirmar su derecho a la diferencia: lengua, tradiciones religiosas, incluso código 
civil, aunque restringido a su territorio, la provincia de Québec. Hacia el exterior, progresando en la afirmación de la nacionalidad canadiense, pero constituida por su doble identidad: anglófona y francófona.

- Finalmente, a partir de los años '70, el nacionalismo de Québec, enarbolando lo que podría denominarse la quebequización (singularidad directamente vinculada a una eclosión cultural autóctona que se conoce como la de «La revolución tranquila»), pone en camino la viabilidad de dos referendums por la soberanía nacional de la Provincia, uno en 1980 y otro en 1995, que la población de Québec rechazó con estrecho margen en las dos ocasiones.

3. Su referencia a una identidad colectiva (especialmente tras «La Revolución tranquila») se reviste de manifestaciones culturales en la educación, el arte, las celebraciones, etc. que sirven para reproducir signos externos de la diferencia frente a las identidades colectivas que han sido su matriz histórica, tanto remota (Francia), como cercana (sus propios partenaires anglófonos de Canadá), yendo a buscar sus fuentes hacia atrás, en la idea de América, incluyendo las primitivas culturas autóctonas, y hacia adelante proyectándose en la solidaridad con las demás culturas fundadoras del Nuevo Mundo.

4. En cualquier caso, su referencia a la identidad colectiva de Québec, se reclama como categoría que transciende a toda contingencia individual (de sexo, de edad, de dotación física o intelectual, etc.), grupal (de hábitat, recursos materiales, profesiones, etc.), y social (de clase, de opción política o religiosa, de compromisos institucionales, etc.), y especialmente debido a la conciencia de la creciente diversidad multiétnica de sus habitantes; pero su proyecto, como el de los nacionalismos en formación del Viejo Mundo, más que hacia la permanencia en el tiempo, se sustenta sobre la conquista del futuro y sobre una independencia nueva en el espacio (territorio); no obstante, el sacrificio personal que se vinculaba en los años '70 a las utopías de la revolución socialista, hoy excluye cualquier género de violencia como distintivo propio 5 .

Así pues, estudiar el nacionalismo de Québec para comprender la mediación comunicativa en la construcción de la identidad colectiva, a través del socioanálisis, pareció una buena elección.

\section{EL DISEÑO DE LA APLICACIÓN DEL SOCIOANÁLISIS AL ESTUDIO DEL NACIONALISMO DE QUÉBEC}

Elegido el nacionalismo de Quebec como objeto material de este estudio sobre la mediación comunicativa en la construcción de la identidad colectiva, se imponía diseñar la constitución de los grupos y la dinámica de las sesiones de

\footnotetext{
5 Como más adelante habrá ocasión de confirmar examinando el discurso de los grupos de discusión.
} 
discusión, de forma que todos los participantes fuesen québequois, y además nacionalistas, pero también de forma que en las sesiones de discusión, el objeto de debate no fuese el nacionalismo, (y tampoco la identidad colectiva de Québec) sino la actualidad política que transmiten los medios. No se olvide que el objetivo inicial de esta investigación es comprobar cómo la mediación comunicativa de la información política de los Medios, (Piñuel y Gaitán, 1995; Piñuel, 1997) resulta a su vez mediatizada por la conciencia de la historia local de cada comunidad. Pero ¿cómo lanzar una convocatoria de grupos de discusión integrados por «nacionalistas», evitando después el riesgo de que el discurso grupal sobre productos mediáticos de actualidad quedase bloqueado por la urgencia de justificar cada cual la propia participación hablando de su apreciación personal del nacionalismo? Había que evitar precisamente que el discurso grupal fuese a girar una y otra vez sobre apreciaciones del nacionalismo, pues éste no era el tema. El tema de discusión tenía que ser otro: es decir, presentados unos productos mediáticos de actualidad, el objeto de discusión tenía que ser esta comunicación mediática, de forma que tras el discurso sobre ella pudiésemos desvelar luego, mediante el análisis, los socioesquemas nacionalistas previos en el imaginario colectivo.

Para resolver el problema, se optó por no decir en la convocatoria de participantes el objetivo verdadero que perseguíamos al constituir los grupos (conocer, a través de la discusión sobre productos mediáticos, el socioesquema del nacionalismo de Québec), sino otro: conocer a través de la discusión entre nacionalistas de diversa índole y nacionalidad (se trataba de una investigación internacional, lo que justificaba que el investigador fuera un español), cuáles eran sus opiniones sobre «El humor y la política en los Medios», pues éste era un tema de gran actualidad y un aspecto que interesaba conocer era si el humor o la burla política publicadas por los Medios, podría ser una causa de banalización y/o de desmovilización política de los ciudadanos.

Esta estratagema podía ofrecer las siguientes ventajas:

1. Elegir estímulos experimentales para desencadenar el debate, que fuesen productos mediáticos humorísticos referidos a la actualidad de la información política y que además, mezclados con otros referidos a la política nacional e internacional reciente, aludiesen a problemas vinculados con el nacionalismo de Québec, pero sin citarlo.

2. Facilitar desde el comienzo la activación de esquemas cognitivos previos sobre su identidad nacional (que luego podrían ser traídos a colación), pues sin disponer de tales esquemas, los productos mediáticos humorísticos seleccionados no podrían comprenderse ni podrían desencadenar la hilaridad, la risa del grupo.

3. Iniciar las sesiones provocando un clima relajado de participación, pues la proyección de los items humorísticos seleccionados, al desencadenar las risas de los participantes, instauraría la complicidad entre ellos para entrar en un vínculo grupal, dispuestos a poner en común el capital cognitivo de su «auto-referencia» nacionalista, pero sin proponérselo. 
$\mathrm{Al}$ objeto de conseguir estos objetivos, la tarea consistiría en seleccionar los items humorísticos más adecuados y en lanzar la convocatoria para constituir los grupos de discusión integrados por participantes nacionalistas, hasta llevar a cabo las sesiones, registrando sus resultados.

Esta tarea fue posible gracias a inestimables apoyos. En primer lugar, la Embajada de Canadá acogió el proyecto y subvencionó mi viaje y estancia en Montreal durante el mes de julio de 2001. Conté igualmente con el apoyo de los Profesores Drs. James Taylor y Gilles Brunnel, de la Universidad de Montréal, que interesados por mi proyecto de investigación, me facilitaron la acogida por parte del Departamento de Comunicación de esta universidad, donde dispuse de recursos materiales y de la inestimable ayuda del Prof. Fabien Cishahajo, en calidad de asistente de investigación.

Para la elección de los items humorísticos como estímulos desencadenantes de la discusión de grupo, se optó por buscar viñetas humorísticas de prensa (es decir, chistes gráficos), pues este género está muy extendido en todos los países y podría utilizarse fácilmente en posteriores fases de este proyecto de investigación en el Continente Europeo ${ }^{6}$.

Pero queríamos también evitar el riesgo de que las viñetas seleccionadas como estímulos desencadenantes de la discusión de grupo, resultasen previamente conocidas por los participantes, ya fuese por la celebridad de su autor, o por la relevancia del Medio que las publicaba, y se perdiera entonces el efecto sorpresa: un chiste pierde gracia cuando se le cuenta a alguien que ya lo sabe. Por esta razón las viñetas seleccionadas, referidas a la actualidad más inmediata al calendario de las discusiones de grupo, pertenecen a los archivos de www.InfiniT.com, sitio de Internet que diariamente ofrece una caricatura del equipo de ilustradores cuyo creativo más importante es Eric Godin, y que también diariamente se difunden por las cadenas de televisión LCN y TVA. Así, el hecho de que las caricaturas fueran de actualidad, estaba garantizado; pero también, como la audiencia de Internet no acumula igual número de lectores que los grandes Medios impresos, y en las cadenas de televisión una caricatura es más fugaz, esperábamos que las caricaturas seleccionadas pudiesen no ser conocidas previamente por los participantes, dato que resultó confirmado. Las caricaturas seleccionadas fueron estas:
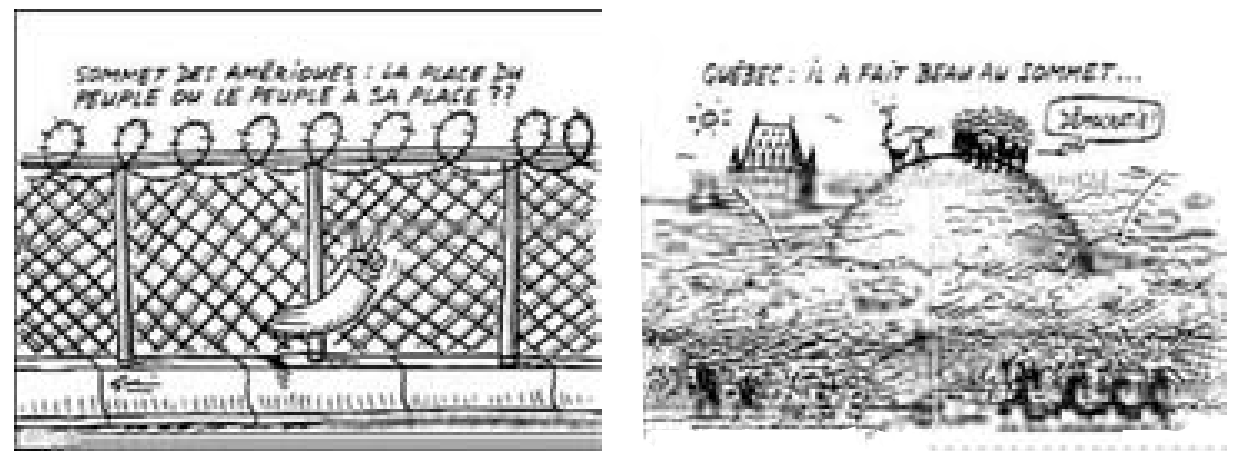

${ }^{6}$ Se desechó la idea inicial de seleccionar secuencias de TV, pues emisiones como las conocidas en España y Francia como «los muñecos del guiñol», no existe en Canadá. 

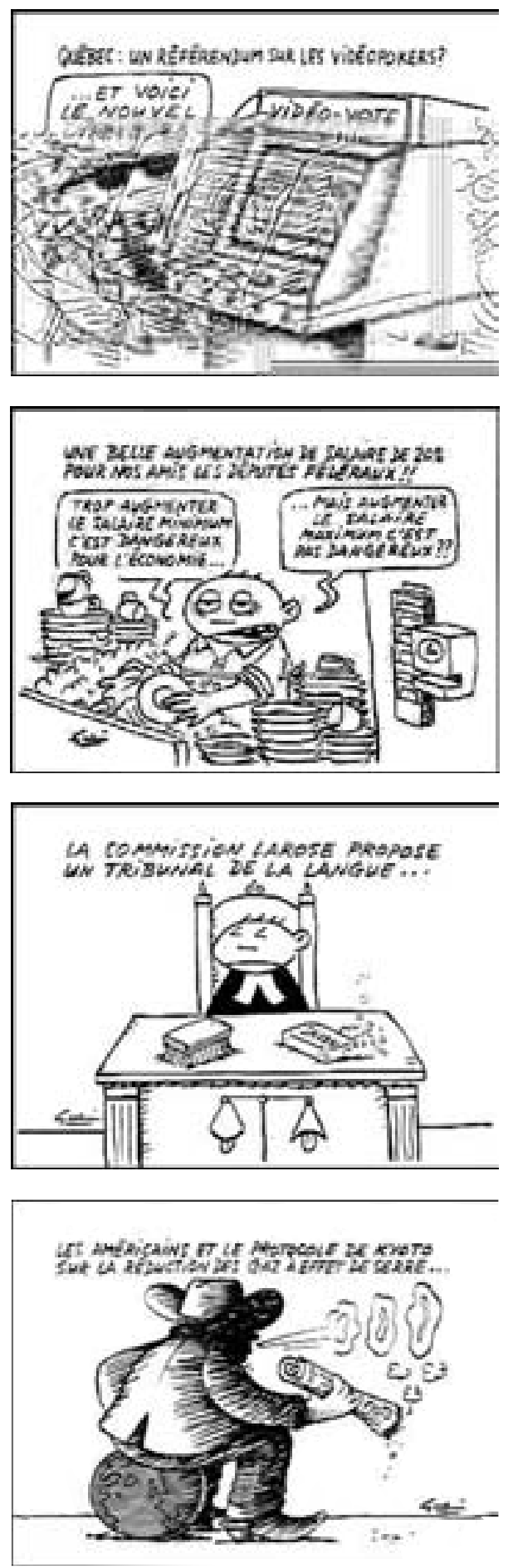
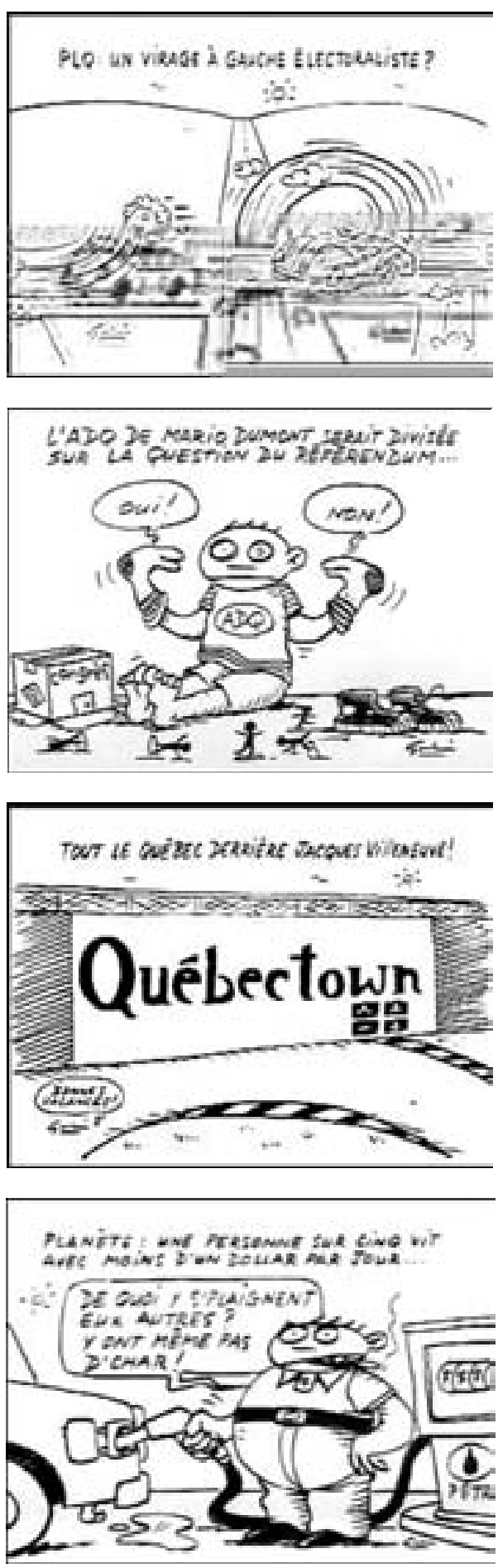


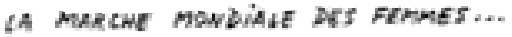
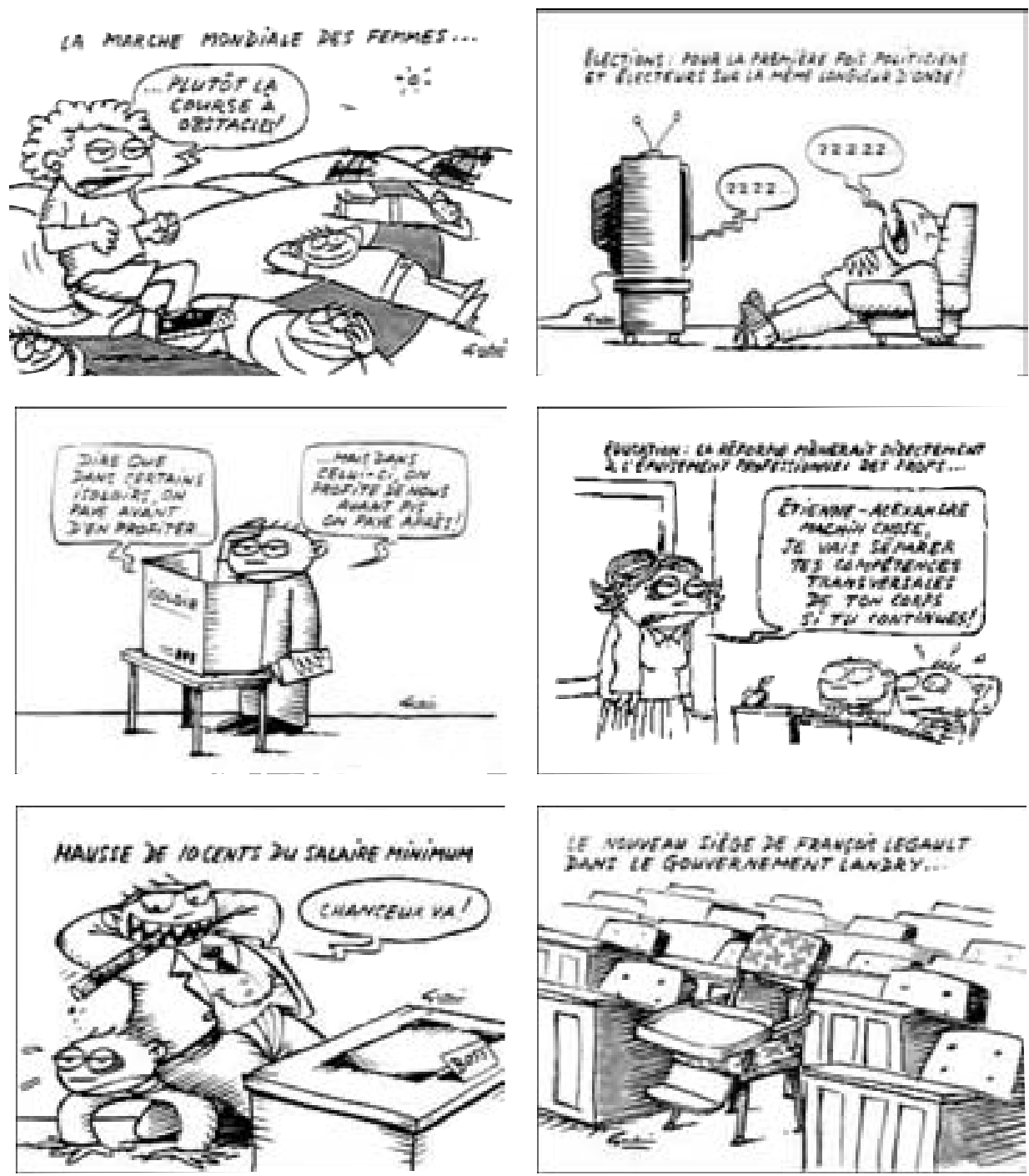

Las sesiones se desarrollarían provistas de un proyector de transparencias, y se elaboró un guión para los mantenedores cuyo texto era éste7:

7 Su traducción es ésta: «Introduccion. Presentar el objetivo de la investigación «Le rire et la politique» (Es decir, se trata de una investigación internacional para conocer a través de la discusión entre nacionalistas de diversa índole y nacionalidad cuáles son sus opiniones sobre «El humor y la política en los Medios», etc). $1^{\underline{a}}$ Fase: mostrar las caricaturas. $2^{\underline{a}}$ Fase: Plantear la primera pregunta: 1) ¿Piensan ustedes que la risa o la burla puede dañar, o no, los sentimientos de participación politica? Discusión. Sólo en el caso de que la discusión se atasque, plantear la segunda pregunta: 2) ¿Piensan ustedes que hay temas tan delicados o tan importantes que no deben ser objeto de mofa? Discusión. Sólo en el caso de que la discusión se atasque, plantear la tercera pre- 
«Introducción. Exposer le but de la recherche: Le rire et la politique.

lère phase: montrer les caricatures

2ème phase: Poser des questions

Première question: 1. Est-ce que le rire blesse ou ne blesse pas les sentiments politiques?

Discussion

S'il y a des blocages, poser la deuxième question: 2. Est-ce qu' il y a des sentiments trop importants ou trop délicats pour faire l'object du rire?

Discussion.

S'il y a des blocages, poser la troisième question: 3) Vous est-il arrivé quelquefois d'être blessés par le rire des non-nationalistes?»

La exposición de los objetivos de la investigación (al decir que se trataba de una investigación internacional para conocer a través de la discusión entre nacionalistas de diversa índole y nacionalidad cuáles eran sus opiniones sobre «El humor y la política en los Medios», etc.) permitió, sin excepciones, no sólo centrar el tema de discusión, sino también ver normal desde el comienzo la presencia de un extranjero, un español, en calidad de investigador principal que se dirigía a ellos recabando sus opiniones.

El visionado de las transparencias desencadenó, también sin excepciones, la hilaridad en todos los grupos; y pudo comprobarse que en todas las ocasiones se instauró la complicidad entre los participantes entrando en un vínculo grupal que se manifestaba mediante gestos y risas aprobatorias para expresar la perfecta comprensión de las caricaturas, dispuestos a poner en común el capital cognitivo de su «auto-referencia» nacionalista. Efectivamente era necesario estar en las claves de la actualidad y en las claves de la política doméstica cotidiana para que la comprensión perfecta de las caricaturas desencadenase la hilaridad del grupo. Un lector español ajeno a estas claves advertirá enseguida que le faltan datos para «entender el chiste» en la mayor parte de estas imágenes; es decir, carece de los «socioesquemas» imprescindibles que, sin embargo, se encontraban a disposición de los participantes ${ }^{8}$.

gunta: 3) ¿Alguna vez les ha sucedido a ustedes sentirse heridos por la burla de los no-nacionalistas?».

${ }^{8}$ Por ejemplo, en torno a la Cumbre de las Américas, saber no sólo que se habían celebrado días atrás (segunda semana de julio de 2001), sino también que, al igual que en la ciudad de Génova con la cumbre del G-8, se había desplegado un escesivo aparato de seguridad; que el debate sobre las experiencias de voto en torno al referéndum de independencia que por dos veces (en 1980 y 1995) perdieron los «independentistas» es un asunto recurrente y a propósito del cual muchas veces se traen a colación, en los debates políticos de los partidos nacionalistas, explicaciones que tienen que ver con la expresión de voto y con las rutinas formales de votación; conocer las controversias de actualidad sobre las iniciativas del PLQ (Partido Liberal Quebequois) y de la ADQ (Alianza Democrática Quebequois); saber qué hace la Comission Larose, quién es Jacques Villeneuve, cuál fue la reacción americana en junio frente al Protolocolo de Kyoto, etc., hasta concluir con la última imagen en la que se hace burla de la juventud de François Legault, miembro del Gobierno Landry... 
Se decidió constituir entre tres y cinco grupos de discusión, uno en Montreal y el resto cubriendo significativamente el territorio de la Provincia de Québec, ya que el interés de la investigación no residía en hallar rasgos comparativos del socioesquema de la identidad quebequois reproducido en los discursos según regiones nacionalistas, o según opciones políticas de partido, o ideológicas (para lo que habría que incrementar el número de grupos), sino según tipo de hábitat: presupuestarias y temporales (el mes de julio es el mes en que todo el mundo parte de vacaciones) hicieron que fracasaran los intentos de constituir un grupo en la capital, Québec, -donde sin embargo se establecieron dos convocatorias- y otro grupo en los alrededores de Saguenay, donde resultaba difícil conseguir, por otra parte, que acudiesen participantes que no fuesen veraneantes, desvirtuando entonces la naturaleza del grupo. En consecuencia, los grupos constituidos, y cuyo discurso fue grabado y trascrito para esta investigación, fueron uno en la gran metrópoli de Montréal, otro en una ciudad de tipo medio con fuerte identidad nacionalista como es Trois Rivières, y finalmente otro en la pequeña población de Boucherville. La transcripción de cada una de las sesiones fue realizada por Fabien Cishahajo, quien además participó en esta investigación gestionando todos los contactos con informantes para lanzar las convocatorias de los grupos, y como moderador en todas las sesiones, presentándole a los participantes al autor de este trabajo, profesor español cuyo acento en la expresión francesa es más europeo que canadiense y que necesitaba de este apoyo para ser aceptado como moderador sin despertar reticencias.

\section{EL SOCIOESQUEMA DEL NACIONALISMO DE QUÉBEC Y LA MEDIACIÓN COMUNICATIVA}

Dado que experimentalmente pudo comprobarse cómo a medida que se proyectaban las caricaturas en la primera fase de las sesiones de los grupos de discusión, se producía la hilaridad en todos los grupos, y que en todas las ocasiones se instauró la complicidad entre los participantes entrando en un vínculo grupal que se manifestaba mediante gestos y risas aprobatorias para expresar la perfecta comprensión de las caricaturas (dispuestos a poner en común el capital cognitivo de su «auto-referencia» nacionalista), la primera categoría del análisis del discurso que cabe rastrear en las transcripciones tiene que ver con esta pregunta: ¿se manifiestan en la expresión del discurso variables y valores tipo, características del nacionalismo, en la identificación y apreciación del género periodístico del humor en la política, que distingan al político, al periodista y al ciudadano? ¿Cómo?

En segundo lugar, supuesto que lleguen a manifestarse algunas de estas variables y valores tipo, capaces de organizar el sentido que el género del humor encierra en la información política de los Medios, ¿cuáles son las «teorías de la mente» 9 en función de las cuales el «acuerdo» que se instaura en el discurso del

\footnotetext{
9 Por ejemplo, saberes o creencias previos que permiten anticipar y complementar la información recibida, y posicionarse cognitiva y afectivamente desde «registros» específicos ante estos productos mediáticos como las caricaturas. Porque las intenciones que se adjudican a una caricatu-
} 
grupo nacionalista otorga identidad a los autores de las caricaturistas y a los Medios que producen este género, así como a los usuarios (lectores) que lo consumen?; o ¿cuáles son las «teorías de la mente» en función de las cuales se atribuye una intencionalidad al discurso que los autores y Medios expresan a través del humor?; y finalmente, ¿cuáles son las creencias y expectativas comprometidas en este género de comunicación?

La tercera categoría de análisis tendría que ver con el universo de la referencia cuando se traen a colación cuestiones vinculadas al nacionalismo de Québec, como es el caso de la mayoría de las imágenes que desencadenan el discurso del grupo En este sentido, el universo de referencia (con mayor o menor riqueza de temas, personajes, acciones, etc.) puede ser planteado en el discurso desde muchas formas de modalidad, entre ellas la aléthica (es decir, lo necesario, lo posible, lo contingente o lo imposible), la epistémica (es decir, lo verificado, lo probable, lo aún no decidido, lo falsado, etc.), la deóntica (es decir, lo obligatorio, lo permitido, lo indiferente, lo prohibido, etc.) o la existencial (o sea, lo universal, lo existente, lo indeterminado, o lo vacío, etc.).

Ahora bien, las expresiones del discurso que en cada caso remitan a esta última categoría pueden a su vez tener que ver con referencias:

a) Las tensiones entre ruptura y continuidad (Bouchard, 2001) frente a las metrópolis históricas, políticas, y/o económicas, propias de cualquier nacionalismo, con sus estrategias de desgajamiento, sus forcejeos por establecer una identidad nacional contrariando su diversidad interna, etc.

b) Un origen que temporalmente tiende a remontarse a generaciones lejanas (desde los pueblos autóctonos, y pasando por los pioneros colonizadores franceses) y espacialmente circunscribiéndose siempre a un territorio para cuya legitimidad en las formas de apropiación y explotación, se encuentra dirimiendo sucesivas peripecias para marcar su independencia, y cuáles.

c) Una identidad colectiva (especialmente tras «La Revolución tranquila») revestida de manifestaciones culturales, y cuáles son éstas en la educación, el arte, las celebraciones, etc. que sirven para reproducir signos externos de la diferencia frente a otras identidades colectivas que han sido su matriz histórica, tanto remota (Francia), como cercana (sus propios partenaires anglófonos de Canadá), yendo a buscar sus fuentes, o hacia atrás (en la idea de América, incluyendo las primitivas culturas autóctonas), o hacia adelante proyectándose en la solidaridad con las demás culturas fundadoras del Nuevo Mundo. Y en cualquier caso,

d) La identidad colectiva de Québec como categoría que transciende a toda contingencia individual (de sexo, de edad, de dotación física o intelectual, etc.), grupal (de hábitat, recursos materiales, profesiones, etc.), y social (de clase, de opción politica o religiosa, de compromisos institu-

ra no son las mismas que se atribuyen a un editorial, un reportaje, una crónica o a las declaraciones de un político en una entrevista, etc. 
cionales, etc.), y cuyo proyecto, como el de los nacionalismos en formación del Viejo Mundo, se lanza, más que hacia la permanencia en el tiempo, hacia la conquista del futuro.

En consecuencia, la parrilla conceptual que nos permitiría obtener un diagnóstico del socioesquema nacionalista quebequois a partir de las expresiones del discurso grupal sobre el humor en la comunicación política de los Medios, sería ésta:

\begin{tabular}{cccccc}
\hline & & \multicolumn{3}{c}{ Categorías de la referencia nacionalista } \\
\cline { 3 - 5 } Categorías & Tensiones & Apelación a & Manifestaciones & Transcendencia \\
Formales & Referencias al & (ruptura y & un origen & culturales de & de la categoría \\
& Género humor & continuidad & (tiempo y espacio) & la diferencia & nacionalista \\
\hline
\end{tabular}

Variables tipo

\begin{tabular}{lccccc}
\hline El político & $(01)$ & $(02)$ & $(03)$ & $(04)$ & $(05)$ \\
\hline El periodista & $(11)$ & $(12)$ & $(13)$ & $(14)$ & $(15)$ \\
\hline El ciudadano & $(21)$ & $(22)$ & $(23)$ & $(24)$ & $(25)$ \\
\hline \multirow{3}{*}{$\begin{array}{c}\text { Categorías } \\
\text { Formales }\end{array}$} & & \multicolumn{5}{c}{ Categorías de la referencia nacionalista } \\
\cline { 2 - 6 } & $\begin{array}{c}\text { Referencias al } \\
\text { Género humor }\end{array}$ & $\begin{array}{c}\text { Tensiones } \\
\text { (rustura y } \\
\text { continuidad }\end{array}$ & $\begin{array}{c}\text { Apelacín a } \\
\text { un origen } \\
\text { (tiempo y espacio) }\end{array}$ & $\begin{array}{c}\text { Manifestaciones } \\
\text { culturales de } \\
\text { la diferencia }\end{array}$ & $\begin{array}{c}\text { Transcendencia } \\
\text { de la categoría } \\
\text { nacionalista }\end{array}$ \\
\hline
\end{tabular}

Teorías de la mente

\begin{tabular}{llllll}
\hline Realidad & $(31)$ & $(32)$ & $(33)$ & $(34)$ & $(35)$ \\
\hline Deseo & $(41)$ & $(42)$ & $(43)$ & $(44)$ & $(45)$ \\
\hline Ficción & $(51)$ & $(52)$ & $(53)$ & $(54)$ & $(55)$ \\
\hline
\end{tabular}

Modalidad expresión

\begin{tabular}{llllll}
\hline Aléthica & $(61)$ & $(62)$ & $(63)$ & $(64)$ & $(65)$ \\
\hline Epistémica & $(71)$ & $(72)$ & $(73)$ & $(74)$ & $(75)$ \\
\hline Deóntica & $(81)$ & $(82)$ & $(83)$ & $(84)$ & $(85)$ \\
\hline Existencial & $(91)$ & $(92)$ & $(93)$ & $(94)$ & $(95)$ \\
\hline
\end{tabular}

Con este instrumental analítico, cualquier observador/lector competente de las transcripciones de los discursos grupales, puede ir asignando secuencias o segmentos del discurso a una o a varias de las 50 categorías (codificadas por dígitos entre paréntesis) que contiene la parrilla, decidiéndolo en función del cruce entre las variables correspondientes a las filas (categorías formales de la 
expresión, como «variables tipo», «teorías de la mente» y «modalidades») y a las columnas (categorías de la referencia, ya sea relativa al género del humor, o bien relativa a rasgos característicos del nacionalismo). En el Análisis que sigue a continuación, pueden consultarse las secuencias del discurso tras la operación de asignación categorial, secuencias que pueden a su vez remitirse a «palabras clave», tal como lo hemos consignado en la columna derecha de cada casilla de categorías, tomando en consideración el tono expresado en las sesiones, aún a riesgo de tener que pasar por alto muchos detalles. Esta última operación es precisamente la que, a mi juicio, nos da las particularidades más relevantes para establecer una visión de conjunto, tal como aparece después en las tablas 1,2, y 3 con que se culmina el Análisis. El lector puede proceder a contemplar esta visión de conjunto ordenando la lectura de las tablas por filas, o por columnas. 
Análisis

\begin{tabular}{|c|c|c|}
\hline $\begin{array}{l}\text { CATEGORÍAS } \\
\text { FORMALES }\end{array}$ & REFERENCIAS AL GÉNERO HUMOR & \\
\hline Variables tipo & Código: (01) & Palabras clave \\
\hline El político & $\begin{array}{l}\text { Ça (le rire) doit les blesser (aux politiciens). Ça (l'hu- } \\
\text { mour) blesse souvent les politiques, les personnes qui } \\
\text { ont de grandes convictions. Le ridicule d'un politicien, } \\
\text { c'est un personnage public après tout, il fait de la politi- } \\
\text { que. Non, ça en principe ça blesse mais à mon avis ce } \\
\text { n'est pas politique. Ça blesse le personnage politique, ca } \\
\text { ne porte pas sur ses sentiments politiques, sur sa façon } \\
\text { de faire la politique. C'est d'une grande méchanceté. } \\
\text { Aussi bien s'attaquer à la grande laideur d'un politicien } \\
\text { ou à la grosseur d'une politicienne, ou encore à l'infir- } \\
\text { mité de Mr Chrétien ou de M. Bouchard, c'est pas poli- } \\
\text { tique finalement. }\end{array}$ & $\begin{array}{l}\text { L'humour bles- } \\
\text { se souvent les } \\
\text { politiciens. }\end{array}$ \\
\hline $\begin{array}{l}\text { CATEGORÍAS } \\
\text { FORMALES }\end{array}$ & $\begin{array}{l}\text { CATEGORÍAS DE LA REFERENCIA } \\
\text { NACIONALISTA: Tensiones (ruptura y continuidad) }\end{array}$ & \\
\hline Variables tipo & Código: (02) & Palabras clave \\
\hline El político & $\begin{array}{l}\text { Dans le domaine du militantisme presque tous les poè- } \\
\text { tes étaient carrément indépendantistes. Et l'on a jamais } \\
\text { vu au Québec un poète fédéraliste, un poète qui chantait } \\
\text { les vertus du fédéralisme, on n'en a jamais vu. Beau- } \\
\text { coup de poètes qui militaient pour le Québec libre et } \\
\text { dans ce sens là le mouvement nationaliste n'était pas } \\
\text { associé à une philosophie rétrograde, conservatrice ou } \\
\text { repliée sur elle-même comme le sont souvent les natio- } \\
\text { nalismes traditionnels comme on en voit en Europe. Et } \\
\text { c'était dans une moindre mesure un nationalisme pro- } \\
\text { gressiste, un nationalisme d'af-franchissement et non } \\
\text { pas un nationalisme expansionniste.C'est de se dire } \\
\text { c'est bien beau l'indépendance. Une fois que l'on a joué } \\
\text { cette carte-là, qu'est ce qu'on fait? Tant qu'on est à l'in- } \\
\text { térieur du Canada, il y a peut-être aussi des choses à fai- } \\
\text { re... On veut le beurre et l'argent du beurre en même } \\
\text { temps. C 'est ça qu'on a tenté de faire très souvent. Tu } \\
\text { noyautes le gouvernement fédéral et puis tu te fais pas- } \\
\text { ser des lois. Trudeau a été la dernière personne à croire } \\
\text { à une idée du Canada, mais il a tout fait pour le réussir. } \\
\text { Avec la richesse que l'Alberta a, ils ont des tas de rai- } \\
\text { sons de se séparer. Ou en tous cas de séparer leur écono- } \\
\text { mie pour avoir plus de pouvoirs. En tout cas ce ne serait }\end{array}$ & $\begin{array}{l}\text { Souvent ce sont } \\
\text { des politiciens - } \\
\text { la souveraineté } \\
\text { et le } \\
\text { fédéralisme, } \\
\text { c'est toujours } \\
\text { une } \\
\text { confrontation } \\
\text { entre le } \\
\text { politiciens. }\end{array}$ \\
\hline
\end{tabular}




\begin{tabular}{|c|c|c|}
\hline & $\begin{array}{l}\text { pas surprenant que ce soit eux qui l'obtiennent en pre- } \\
\text { miers, justement parce qu'ils sont tellement riches que } \\
\text { ça leur donne le pouvoir de négocier. Le projet politique } \\
\text { du PQ (parti Québecois) ils n'ont jamais su se renouve- } \\
\text { ler. Pour vendre le projet souverainiste à la population, } \\
\text { ils chialent contre le fédéral,. Le discours est tellement } \\
\text { ambigu. On sent qu'ils jouent pour faire avancer le pro- } \\
\text { jet souverainiste. Moi j'ai pas besoin de me séparer du } \\
\text { Canada pour parler français et m'affirmer comme Qué- } \\
\text { becois. Que je sois au Canada ou aux USA, je m'en } \\
\text { fous. Ca, c'est un discours de colonisé je trouve. Un } \\
\text { colonisé - Ceinture flichie, patriote - je suis contre tout } \\
\text { ça. On parlait tout à l'heure d'ouverture sur le monde. } \\
\text { Le Québec est très ouvert sur le monde. Souvent ce sont } \\
\text { des politiciens - la souveraineté et le fédéralisme, c'est } \\
\text { toujours une confrontation entre le politiciens. La popu- } \\
\text { lation est perdue. Ça les sert énormement. Puis là il y a } \\
\text { le parti libiral du Québec. Un vers de terre giant qui } \\
\text { rampe. C'est pourquoi je vote pourle PQ, non pas que je } \\
\text { sois pour la souveraineté, mais le parti libiral, c'est } \\
\text { minable. C'est tout petit. Je vote pour le PQ parce que } \\
\text { c'est un parti qui bouscule les choses. Ils suscitent le } \\
\text { débat, contraiement au parti libiral qui lui fait des cour- } \\
\text { bettes devant le fédéral. }\end{array}$ & \\
\hline $\begin{array}{l}\text { CATEGORÍAS } \\
\text { FORMALES }\end{array}$ & $\begin{array}{l}\text { CATEGORÍAS DE LA REFERENCIA } \\
\text { NACIONALISTA: } \\
\text { Apelación a un origen (tiempo y espacio) }\end{array}$ & \\
\hline Variables tipo & Código: (03) & Palabras clave \\
\hline El político & $\begin{array}{l}\text { Il faut regarder ce qui s'est passé au Manitoba. C'est } \\
\text { presque un génocide culturel qui s'est fait au début du } \\
\text { siècle en fermant les écoles. À cause du passage de Tru- } \\
\text { deau, dans la constitution, on a forcé le gouvernement } \\
\text { du Manitoba de traduire toutes ses lois en français. C'est } \\
\text { quand même important. Je sais bien que tu vas me dire } \\
\text { que ca ne correspond pas à la réalité, mais au niveau des } \\
\text { institutions, c'est important. Quand j'ai apporté cet } \\
\text { exemple, c'est pour te montrer de quelle façon souvent } \\
\text { peuvent raisonner les Québécois. Historiquement, il faut } \\
\text { reconnaître quand même le rôle du parti libéral. C'est le } \\
\text { parti libéral qui a fait la révolution tranquille ici après } \\
\text { une période de conservatisme, de droite avec l'Union } \\
\text { nationale. Tous les changements majeurs qu'il y a eus } \\
\text { dans la révolution tranquille, la santé, l'éducation, la }\end{array}$ & $\begin{array}{l}\text { Le Québec est } \\
\text { aujourd' hui } \\
\text { considiré } \\
\text { comme une } \\
\text { province parmi } \\
\text { d'au-tres. Et } \\
\text { pourtant le } \\
\text { Canada ça } \\
\text { vient d'ici. }\end{array}$ \\
\hline
\end{tabular}




\begin{tabular}{|c|c|c|}
\hline & $\begin{array}{l}\text { nationalisation de l'électricité dans les années 60, avec } \\
\text { René Levesque. Il était ministre des Ressources nature- } \\
\text { lles, c'est lui qui a privatisé l'électricité C'est ça. Ça a } \\
\text { quand même été fait par le parti libéral. Plusieurs lea- } \\
\text { ders du parti libéral ont quitté ce parti et ont fondé le } \\
\text { parti Québécois et depuis les années } 70 \text {, le parti libéral } \\
\text { est devenu un parti plus à droite, un parti au service de } \\
\text { la grande bourgeoisie et du capital. Tandis que le parti } \\
\text { québécois était un parti au départ socio-démocrate, près } \\
\text { de la petite bourgeoisie et de la bourgeoisie montante. } \\
\text { C'est vrai que le parti québécois s'est fait doubler par } \\
\text { des gens qui veulent maintenant former un parti de gau- } \\
\text { che, et le parti libéral lui se dit plus à gauche parce qu'il } \\
\text { a fait élire une travailleuse sociale dans une élection } \\
\text { partielle. En fait ils sont très faibles. Et ils acceptent de } \\
\text { tas de chose qui viennent des libéraux fédéraux parce } \\
\text { qu'ils sont libéraux. Il y a des choses que le libéral } \\
\text { fédéral fait et qui sont inacceptables, mais ils ne peuvent } \\
\text { pas vraiment s'insurger parce que ce serait presque aller } \\
\text { du côté du parti québécois. Les Anglophones n'ont } \\
\text { jamais voulu du fédéralisme depuis } 1867 \text {. Puis nous on } \\
\text { a toujours voulu collaborer, puis c'est pourquoi on a ins- } \\
\text { tauré le fédéralisme. En bout de ligne au lieu de l'ami- } \\
\text { liorer, ils l'ont centralisé avec l'aide de la cour supreme } \\
\text { d'ailleurs. Les imptôs, c'est le government fédéral. Et } \\
\text { jamais le retour du balancier n'est venu. Le Québec est } \\
\text { aujourd'hui considiré comme une province parmi d'au- } \\
\text { tres. Et portant le Canada ça vient d'ici. }\end{array}$ & \\
\hline $\begin{array}{l}\text { CATEGORÍAS } \\
\text { FORMALES }\end{array}$ & $\begin{array}{l}\text { CATEGORÍAS DE LA REFERENCIA } \\
\text { NACIONALISTA: } \\
\text { Manifestaciones culturales de la diferencia }\end{array}$ & \\
\hline Variables tipo & Código: (04) & Palabras clave \\
\hline El político & $\begin{array}{l}\text { Il y a en effet chez nos politiciens des aspects qui sont } \\
\text { tout aussi drôles, que dans les leurs, dans les fédéralis- } \\
\text { tes, puis on en rit. Il y a eu le cas du chef du bloc Qué- } \\
\text { bécois, Gilles Duceppe, coiffé du bonnet de Serge Cha- } \\
\text { pleau. Au Québec, l'humour, les humoristes, tant à la } \\
\text { télévision que sur scène, semblent avoir évacué complè- } \\
\text { tement cette dimension-là. Or, les canadiens anglais eux } \\
\text { sont très critiques à l'égard de leurs élites politiques. Je } \\
\text { dois vous dire qu'ils ont une façon aussi de traiter la } \\
\text { question nationale québécoise, des enjeux, de Lucien } \\
\text { Bouchard, qui vise à nous faire rire. }\end{array}$ & $\begin{array}{l}\text { Il y a chez nos } \\
\text { politiciens des } \\
\text { aspects drôles } \\
\text { aussi dans les } \\
\text { uns que dans } \\
\text { les autres: puis } \\
\text { on en rit. }\end{array}$ \\
\hline
\end{tabular}




\begin{tabular}{|c|c|c|}
\hline $\begin{array}{l}\text { CATEGORÍAS } \\
\text { FORMALES }\end{array}$ & $\begin{array}{l}\text { CATEGORÍAS DE LA REFERENCIA } \\
\text { NACIONALISTA: } \\
\text { Transcendencia de la categoría nacionalista }\end{array}$ & \\
\hline Variables tipo & Código: (05) & Palabras clave \\
\hline El político & $\begin{array}{l}\text { Dans le domaine du militantisme presque tous les poè- } \\
\text { tes étaient carrément indépendantistes. Et l'on a jamais } \\
\text { vu au Québec un poète fédéraliste, un poète qui chantait } \\
\text { les vertus du fédéralisme, on n'en a jamais vu. Beau- } \\
\text { coup de poètes qui militaient pour le Québec libre et } \\
\text { dans ce sens là le mouvement nationaliste n'était pas } \\
\text { associé à une philosophie rétrograde, conservatrice ou } \\
\text { repliée sur elle-même comme le sont souvent les Natio- } \\
\text { nalismes traditionnels comme on en voit en Europe. On } \\
\text { disait que le PQ est social-démocrate, mais c'était tout } \\
\text { simplement conjoncturel. Il était très peu différent du } \\
\text { parti libéral. Si on regarde très près les institutions du } \\
\text { parti libéral, le PQ en a profité. D'une part on fait } \\
\text { miroiter l'idée du nationalisme, l'indépendance, mais } \\
\text { on n'a pas de projet de société puis on dit c'est quand on } \\
\text { aura ces outils là qu'on va faire une société très diffé- } \\
\text { rente. Il a eu quand même une forte présence sur la scè- } \\
\text { ne internationale. Trudeau, je pense qu'il a fait un exce- } \\
\text { llent travail. Il n'était pas à la remorque de la politique } \\
\text { américaine. Il a renoué avec la Chine alors que c'était } \\
\text { très mal vu par les Américains à l'époque, avec Cuba. } \\
\text { C'est quand même fantastique, l'ironie de l'histoire. } \\
\text { Cuba qui accueille nos anciens felquistes, Castro qui } \\
\text { devient l'ami personnel de Pierre Elliot Trudeau, qui } \\
\text { avait déclaré la guerre aux FLQ,... }\end{array}$ & $\begin{array}{l}\text { D'une part le } \\
\text { politicien fait } \\
\text { miroiter l'idée } \\
\text { du nationaisme, } \\
\text { l'indépendance, } \\
\text { mais on n'a pas } \\
\text { de projet de } \\
\text { société. }\end{array}$ \\
\hline $\begin{array}{l}\text { CATEGORÍAS } \\
\text { FORMALES }\end{array}$ & REFERENCIAS AL GÉNERO HUMOR & \\
\hline Variables tipo & Código: (11) & Palabras clave \\
\hline El periodista & $\begin{array}{l}\text { Les caricaturistes ont une grande marge de manœuvre } \\
\text { par rapport au éditorialistes Ils ont une certaine impuni- } \\
\text { té. On les considère un peu comme les fous du roi. Mais } \\
\text { les caricaturistes sont les éditorialistes les plus influents. } \\
\text { Ce que font les caricaturistes, c'est de dénoncer la } \\
\text { démagogie (des politiciens). Je ne crois pas que l'hu- } \\
\text { mour dans la caricature ait besoin d'être blessant pour } \\
\text { porter. Les caricaturistes, cherchent à faire ça (ridiculi- } \\
\text { ser) systématiquement. Mais il arrive aussi au caricatu- }\end{array}$ & $\begin{array}{l}\text { On les } \\
\text { considère (les } \\
\text { caricaturistes) } \\
\text { un peu comme } \\
\text { les fous du roi. }\end{array}$ \\
\hline
\end{tabular}




\begin{tabular}{|c|c|c|}
\hline & $\begin{array}{l}\text { riste de faire quelque chose de plus humain, de moins } \\
\text { dérangeant. Si par exemple il y a un politicien ou un } \\
\text { columnist qui meurt, il désire lui rendre hommage. }\end{array}$ & \\
\hline $\begin{array}{l}\text { CATEGORÍAS } \\
\text { FORMALES }\end{array}$ & $\begin{array}{l}\text { CATEGORÍAS DE LA REFERENCIA } \\
\text { NACIONALISTA: } \\
\text { Tensiones (ruptura y continuidad) }\end{array}$ & \\
\hline Variables tipo & Código: (12) & Palabras clave \\
\hline El periodista & $\begin{array}{l}\text { Il ne faut pas oublier que pour les canadiens anglais } \\
\text { Lucien Bouchard est non seulement un ennemi politi- } \\
\text { que, mais l'incarnation du mal Pour le Canada } \\
\text { anglais... le Canada anglais connaît très mal nos politi- } \\
\text { ciens. Il n'en sait que ce qu'e disent les caricaturistes du } \\
\text { Canada anglais. Lucien Bouchard comme autrefois } \\
\text { René Levesque ou autres était connu comme l'incarna- } \\
\text { tion du mal, du nazisme. La perception que les Cana- } \\
\text { diens anglais, les Américains et les étrangers en général } \\
\text { ont du nationalisme Québécois est une perception tron- } \\
\text { quée. Les Canadiens anglais ont depuis quelques temps } \\
\text { à la TV des émissions d'humour. C'est très étonnant } \\
\text { parce que ce sont des émissions qui visent particulière- } \\
\text { ment les politiciens, ce qui n'existe plus ici au Québec. }\end{array}$ & $\begin{array}{l}\text { La perception } \\
\text { que les } \\
\text { Canadiens } \\
\text { anglais, les } \\
\text { Américains et } \\
\text { les étrangers en } \\
\text { général ont du } \\
\text { nationalisme } \\
\text { Québécois est } \\
\text { une perception } \\
\text { tronquée. }\end{array}$ \\
\hline $\begin{array}{l}\text { CATEGORÍAS } \\
\text { FORMALES }\end{array}$ & $\begin{array}{l}\text { CATEGORÍAS DE LA REFERENCIA } \\
\text { NACIONALISTA: } \\
\text { Apelación a un origen (tiempo y espacio) }\end{array}$ & \\
\hline Variables tipo & Código: (13) & Palabras clave \\
\hline El periodista & & \\
\hline $\begin{array}{l}\text { CATEGORÍAS } \\
\text { FORMALES }\end{array}$ & $\begin{array}{l}\text { CATEGORÍAS DE LA REFERENCIA } \\
\text { NACIONALISTA: } \\
\text { Manifestaciones culturales de la diferencia }\end{array}$ & \\
\hline Variables tipo & Código: (14) & Palabras clave \\
\hline El periodista & $\begin{array}{l}\text { Un caricaturiste a montré un castor en train de ronger la } \\
\text { jambe de bois de Lucien Bouchard. À un certain }\end{array}$ & $\begin{array}{l}\text { Ils (les } \\
\text { anglophones) }\end{array}$ \\
\hline
\end{tabular}




\begin{tabular}{|c|c|c|}
\hline & $\begin{array}{l}\text { moment il y a une limite à ne pas franchir. Après la cam- } \\
\text { pagne électorale, Serge Chapleau a fait une autre carica- } \\
\text { ture hommage à Gilles Ducepp. On devrait aussi dénon- } \\
\text { cer tous les caricaturistes qui ont dessiné Jean Chrétien } \\
\text { en mettant l'accent sur sa bouche croche ou quelque } \\
\text { chose comme ça. On s'attaque à son intégrité physique } \\
\text { exactement comme Bouchard avec sa jambe. Lucien } \\
\text { Bouchard et sa jambe de bois, si on trouve ça horrible. } \\
\text { Aussi bien s'attaquer à la grande laideur d'un politicien } \\
\text { ou à la grosseur d'une politicienne, ou encore à l'infir- } \\
\text { mité de Mr Chrétien ou de M. Bouchard, c'est pas poli- } \\
\text { tique finalement. Ils ont fait une caricature qui était } \\
\text { méchante, mais... je ne sais pas si les canadiens anglais } \\
\text { ont beaucoup ri, mais nous on n'a pas ri. (Oui, mais } \\
\text { quand même, parce que c'est un ennemi politique ) } \\
\text { C'est de voir un castor, en train de tronçonner une jam- } \\
\text { be de bois. Ça c'est une image qui est trop forte. Cela } \\
\text { dit, il n'y a personne qui peut mieux faire que Lucien } \\
\text { Bouchard avec sa canne et sa jambe de bois. Puis main- } \\
\text { tenant on fait des gags avec sa canne aussi. Dans les } \\
\text { journaux anglais on laisse sous-entendre que quelqu'un } \\
\text { qui parle anglais au Québec est directement dénoncé par } \\
\text { la Gestapo. C'est une caricature. Le cinema canadien } \\
\text { tend à être plus conservateur que le cinema Quebecois. } \\
\text { En plus le cinema Quebecois ils vont plus prendre la } \\
\text { parole sur la politique que les Canadiens anglais. Dans } \\
\text { le cinema Quebecois, on va avoir Tabarnak de fédéralis- } \\
\text { te. Ils vont le dire. Mais les Anglophones c'est les seuls } \\
\text { qui vont faire une émission où ils vont rire des politi- } \\
\text { ciens. Ils ont un côté humoristique qui peut rire des poli- } \\
\text { ticiens. L'emission, c'est This hour has } 22 \text { minutes. } \\
\text { C'est ce que je trouve le fun. Sinon, on ne rit plus de la } \\
\text { politique. On ne fait que chealer tout le temps. Je trouve } \\
\text { ça rebarbatif. Les Anglophones vont regarder ca. }\end{array}$ & $\begin{array}{l}\text { ont un côté } \\
\text { humoristique } \\
\text { qui peut rire } \\
\text { des politiciens. }\end{array}$ \\
\hline $\begin{array}{l}\text { CATEGORÍAS } \\
\text { FORMALES }\end{array}$ & $\begin{array}{l}\text { CATEGORÍAS DE LA REFERENCIA } \\
\text { NACIONALISTA: } \\
\text { Transcendencia de la categoría nacionalista }\end{array}$ & \\
\hline Variables tipo & Código: (15) & Palabras clave \\
\hline El periodista & $\begin{array}{l}\text { Écoutez il y a un humoriste américain qui est venu } \\
\text { ici au Québec et qui disait - vous savez, c'est le seul } \\
\text { endroit au monde où quand on entend parler français } \\
\text { on aime pas ça. Écoutez, allez vous promener à New } \\
\text { York avec un accent français, tout le monde va rire }\end{array}$ & $\begin{array}{l}\text { Un humoriste } \\
\text { américain venu } \\
\text { au Québec di- } \\
\text { sait: c'est le } \\
\text { seul endroit au }\end{array}$ \\
\hline
\end{tabular}




\begin{tabular}{|c|c|c|}
\hline & $\begin{array}{l}\text { de la langue. Il y a une époque pas très lointaine, on } \\
\text { nous appelait des frogs, des canadian French frogs, } \\
\text { etc. Pour eux le fait français c'est la France. Ils nous } \\
\text { appellent frog parce que les français mangent des } \\
\text { grenouilles alors qu'ici on en mange même pas de } \\
\text { grenouilles. Ils confondent tout. Remarquez aussi } \\
\text { que au Quèbec, la plupart des humoristes sont natio- } \\
\text { nalistes. Il n'y a pasd'humour antinationalistes au } \\
\text { Quèbec. }\end{array}$ & $\begin{array}{l}\text { monde où on } \\
\text { entend parler } \\
\text { français et on } \\
\text { n'aime pas ça. }\end{array}$ \\
\hline $\begin{array}{l}\text { CATEGORÍAS } \\
\text { FORMALES }\end{array}$ & REFERENCIAS AL GÉNERO HUMOR & \\
\hline Variables tipo & Código: (21) & Palabras clave \\
\hline El ciudadano & $\begin{array}{l}\text { Il y en a peut-être qui lisent les éditoriaux, mais tout } \\
\text { le monde regarde les caricatures. Ça dure le temps du } \\
\text { rire, tout simplement. Si on rit des sentiments de qui } \\
\text { que ce soit, que ce soit de la politique ou d'autres } \\
\text { choses, c'est sur que ça blesse.Quelqu'un qui fait une } \\
\text { caricature pour blesser, ridiculiser quelqu'un ou quel- } \\
\text { que chose, ce que l'on croit ou ce que l'on aime, une } \\
\text { conviction, ça blesse momentanément. Mais si on se } \\
\text { rend compte que la personne qui veut faire de l'hu- } \\
\text { mour ou qui veut faire la blague avec la caricature, ils } \\
\text { sont au courant, qu'ils sont renseignés, c'est plus } \\
\text { acceptable que s'ils étaient ignorants ou comme ca a } \\
\text { été longtemps ou comme c'est encore dans une gros- } \\
\text { se partie du Canada anglais. Les Canadiens anglais } \\
\text { connaissent un peu plus les Québécois que les améri- } \\
\text { cains peuvent les connaître, mais c'est pas une garan- } \\
\text { tie Et puis en général, je pense que si on marche dans } \\
\text { les rues de Regina ou Vancouver et même Toronto et } \\
\text { qu'on demande à l'homme de la rue ce qu'il pense du } \\
\text { nationalisme Québécois, je crois qu'il va dire que les } \\
\text { nationalistes Québécois sont des gens de droite, réac- } \\
\text { tionnaires et tout ca,. alors que nous on est mal } \\
\text { perçus mal connus à l'étranger, parce qu'on charrie } \\
\text { des images qui ne correspondent pas à la réalité. Je } \\
\text { trouve que les Canadiens anglais ont plus de choses à } \\
\text { dire du point de vue de l'humour que les Québécois. } \\
\text { Ils sont pas mal plus actifs sur le chapitre de la politi- } \\
\text { que. Rire de la langue, oui. Quand on est classé com- } \\
\text { me des Canadiens français à cause de la langue, mais } \\
\text { il y a une si grande partie de l'humour qui s'adresse à } \\
\text { nous? }\end{array}$ & $\begin{array}{l}\text { Il y en a peut- } \\
\text { être qui lisent } \\
\text { les éditoriaux, } \\
\text { mais tout le } \\
\text { monde regarde } \\
\text { les caricatures. }\end{array}$ \\
\hline
\end{tabular}




\begin{tabular}{|c|c|c|}
\hline $\begin{array}{l}\text { CATEGORÍAS } \\
\text { FORMALES }\end{array}$ & $\begin{array}{l}\text { CATEGORÍAS DE LA REFERENCIA } \\
\text { NACIONALISTA: } \\
\text { Tensiones (ruptura y continuidad) }\end{array}$ & \\
\hline Variables tipo & Código: (22) & Palabras clave \\
\hline El ciudadano & $\begin{array}{l}\text { Ils (en Alberta) sont pas mal plus actifs sur le chapitre de } \\
\text { la politique. Ils viennent (en Alberta) de fonder un parti } \\
\text { nationaliste. Puis en plus leurs politiciens leurs obtien- } \\
\text { nent des avantages importants. Nous nos politiciens qué- } \\
\text { bécois nous ont rarement obtenu une grande richesse. Les } \\
\text { Albertains sont en train d'obtenir beaucoup d'avantages. } \\
\text { Moi j'ai des amis en Aberta, puis ils ne payent pratique- } \\
\text { ment pas d'impôt, ils payent pas de taxes, ils ont des } \\
\text { emplois, c'est sûr que le emplois ont changé de secteur en } \\
\text { Alberte, mais ils sont beaucoup plus riches que nous. Puis } \\
\text { le gouvernement qui arrive et qui offre tous ces avanta- } \\
\text { ges-là a beaucoup plus de possibilités d'avoir tout le } \\
\text { monde pour les appuyer que nous qui sommes en train de } \\
\text { perdre notre système social, l'éducation va mal, mais ils } \\
\text { ont leurs hôpitaux, leurs écoles et ils vont appuyer leur } \\
\text { gouvernement provincial quand le gouvernement provin- } \\
\text { cial va réclamer plus de pouvoir à Ottawa. Une fois il y a } \\
\text { quelqu'un qui m'a dit : Eh! Tu étudies en anglais et tu te } \\
\text { dis nationaliste? Séparatiste? Comment tu fais pour ne } \\
\text { pas détester les anglais? J'ai dit je n'aime pas Franco, je } \\
\text { n'aime pas Pinochet, et je parle bien l'espagnol aussi. } \\
\text { Vous savez que les grands nationalistes aussi Lucien Bou- } \\
\text { chard, est marié avec une américaine... La reine d'Angle- } \\
\text { terre? Les jokes, c'est au sujet de la monnaie canadienne. } \\
\text { On fait des jokes parce que ca vaut } 65 \text { sous amiricains. } \\
\text { Pas avec la Reine. Pas par rapport à la reine. On va chan- } \\
\text { ger les billets de banque pour qu'il n'y ait plus la figure } \\
\text { de la reine, on s'en fout completement. }\end{array}$ & $\begin{array}{l}\text { Ils (en Alberta) } \\
\text { sont pas mal } \\
\text { plus actifs que } \\
\text { nous sur le } \\
\text { chapitre de la } \\
\text { politique (d'in- } \\
\text { dependence) }\end{array}$ \\
\hline $\begin{array}{l}\text { CATEGORÍAS } \\
\text { FORMALES }\end{array}$ & $\begin{array}{l}\text { CATEGORÍAS DE LA REFERENCIA } \\
\text { NACIONALISTA: } \\
\text { Apelación a un origen (tiempo y espacio) }\end{array}$ & \\
\hline Variables tipo & Código: (23) & Palabras clave \\
\hline El ciudadano & $\begin{array}{l}\text { Historiquement, depuis les } 40 \text { dernières années, les } \\
\text { francophone les plus militants sont nationalistes. Il y a } \\
\text { des francophones qui ne sont pas nationalistes mais ils } \\
\text { sont apolitiques. Mais il y a des francophones qui sont } \\
\text { dans des formations politiques au niveau fédéral, mais }\end{array}$ & $\begin{array}{l}\text { Historiquement, } \\
\text { les francophone } \\
\text { les plus } \\
\text { militants sont } \\
\text { nationalistes. }\end{array}$ \\
\hline
\end{tabular}




\begin{tabular}{|c|c|c|}
\hline & $\begin{array}{l}\text { ce ne sont pas des représentants d'un mouvement iden- } \\
\text { tifiable auquel on peut rattacher un certain progressis- } \\
\text { me. Pratiquement les francophones depuis la révolution } \\
\text { tranquille, depuis 1960, militent du côté du progrès au } \\
\text { Québec, alors qu'avant la révolution tranquille, avant } \\
\text { 1960, le nationalisme était associé à des valeurs conser- } \\
\text { vatrices, religieuses, un nationalisme pas trop dangereu- } \\
\text { ses qui ne remettait pas en cause le pouvoir, qui n'exige- } \\
\text { ait pas l'indépendance politique. On vit dans une bizarre } \\
\text { de situation. Le Québec, gographiquement, d'abord il } \\
\text { est bizarrement placé : je ne sais pas si vous avez en tête } \\
\text { la carte du Canada, mais effectivement il est bizarre- } \\
\text { ment placé. Ceux qui arrivent ici, comme on n'est pas } \\
\text { un pays, ils viennent comme citoyens canadiens. Ils } \\
\text { arrivent ici, ce sont des immigrants, le Canada les } \\
\text { accueille. C'est pas le Québec, on n'est pas un pays } \\
\text { donc on ne les accueille pas. Comme la langue est à } \\
80 \% \text { anglaise, ils vont adopter la langue du pays. Alors } \\
\text { nous on est un tout petit peu perdants là-dedans. }\end{array}$ & \\
\hline $\begin{array}{l}\text { CATEGORÍAS } \\
\text { FORMALES }\end{array}$ & $\begin{array}{l}\text { CATEGORÍAS DE LA REFERENCIA } \\
\text { NACIONALISTA: } \\
\text { Manifestaciones culturales de la diferencia }\end{array}$ & \\
\hline Variables tipo & Código: (24) & Palabras clave \\
\hline El ciudadano & $\begin{array}{l}\text { Il ne faut pas oublier que pour les canadiens anglais } \\
\text { Lucien Bouchard est non seulement un ennemi politi- } \\
\text { que, mais l'incarnation du mal Pour le Canada } \\
\text { anglais... le Canada anglais connaît très mal nos politi- } \\
\text { ciens. Lucien Bouchard comme autrefois René Leves- } \\
\text { que ou autres était connu comme l'incarnation du mal, } \\
\text { du nazisme. La perception que les Canadiens anglais, } \\
\text { les Américains et les étrangers en général ont du natio- } \\
\text { nalisme Québécois est une perception tronquée. Et } \\
\text { beaucoup de gens ne nous ont pas compris et ont véhi- } \\
\text { culé à notre sujet toutes sortes d'images, en nous asso- } \\
\text { ciant, nous les indépendantistes Québécois, à des mou- } \\
\text { vements réactionnaires. Ce n'est pas du tout le cas. Pour } \\
\text { revenir à la question sur la minorité anglophones, je } \\
\text { pense que la minorité anglophone du Québec est } 100 \\
\text { fois mieux traitée que la minorité francophones au } \\
\text { Canada. Dans les journaux anglais on laisse sous-enten- } \\
\text { dre que quelqu'un qui parle anglais au Québec est direc- } \\
\text { tement dénoncé par la Gestapo. C'est une caricature. La } \\
\text { minorité anglophone ici est choyée comme ça ne se peut }\end{array}$ & $\begin{array}{l}\text { La minorité an- } \\
\text { glophone du } \\
\text { Québec est } 100 \\
\text { fois mieux trai- } \\
\text { tée que la } \\
\text { minorité } \\
\text { francophone au } \\
\text { Canada. }\end{array}$ \\
\hline
\end{tabular}


pas. Jusque en 1980, il y avait deux universités anglophones et une université francophone alors que les proportions démographiques sont inversées. Il a fallu attendre 1970 pour avoir une deuxième université francophone ici. Les universités anglophones particulièrement McGill, aujourd'hui, sont les universités les plus prestigieuses au Canada. les Anglais peuvent très bien vivre ici Ils ont toutes les chaînes de télévision, ils ont tous les films en anglais... Les Québécois francophones qui sortent du secondaire parlent peu ou pas l'anglais. Mais parce qu'on a obligé les anglophones à étudier le français, ...Pas pour longtemps. C'est justement pour cette raison qu'il faut leur lever le chapeau. Les anglophones qui sortent de l'école secondaire parlent très bien le français. Ils ont une connaissance fonctionnelle du français et ils peuvent s'exprimer en français en sortant du secondaire et tu ne peux pas dire ça des francophones du Québec en dehors de Montréal et de certaines villes très anglophones. Les anglophones ils ont dit, vous voulez qu'on l'apprenne et ils l'ont appris. Parce qu'on les a obligés. Tu l'as dit. Parce que les anglophones du Québec ne se considèrent pas comme minoritaires. Pour eux, leur pays c'est le Canada. C'est nous qui sommes minoritaires. Ils ne considèrent pas qu'il existe un État qu'on appelle le Québec et où nous sommes $80 \%$. Ça ne compte pas. On est dans un pays qu'on appelle le Canada et nous sommes $25 \%$, peut-être même $22-23 \%$. Ils ne se considèreront jamais comme une minorité. Mais moi je pense qu'ils ont vraiment très bien fait les choses. On leur a dit vous devez apprendre le français et ils l'ont bien appris. Dans dix ans ça va donner que si on offre des emplois aux personnes bilingues, ca va être encore eux qui vont l'avoir. les francophones parlent très peu anglais. Il y a $60 \%$ des professeurs d'anglais au Québec qui ne sont pas capables de tenir une conversation. N'empêche que les anglais ont cette assurance que leur confère leur argent. C'est important. Le fait qu'ils se considèrent comme majoritaires non seulement au Canada, mais dans un continent anglophone et de plus en plus sur la planète entière. Cette arrogance qu'ont nos amis anglophones n'est pas l'exclusivité des anglophones québécois, mais des anglophones du monde entier qui voyagent partout et voient quelqu'un qui parle et qui disent : you don't speak English. Il faut savoir aussi qu'au Quèbec et dans le reste du Canada aussi les jeunes n'aiment pas la politique. Les humoristes n'ont pas tendance à faire des jokes là-dessus. Parce que jeunes ne connaissent rien. Mais c'est à cause du 


\begin{tabular}{|c|c|c|}
\hline & $\begin{array}{l}\text { public. Les jeunes ne sont pas politisés. Quand on avait } \\
20 \text { ans nous on était trés politisés. Moi je ne suis pas } \\
\text { d'accord. Aujourd'hui on est très politisés mais pas sur } \\
\text { la question nationale. Ils sont très politisés sur la ques- } \\
\text { tion des OGM. Ils sont très sensibilisés à d'autres ques- } \\
\text { tions politiques, environnementales, etc. Effectivement, } \\
\text { les jeunes sont très politisés par exemple sur la question } \\
\text { de l'environnement. C'est pas la même chose. }\end{array}$ & \\
\hline $\begin{array}{l}\text { CATEGORÍAS } \\
\text { FORMALES }\end{array}$ & $\begin{array}{l}\text { CATEGORÍAS DE LA REFERENCIA } \\
\text { NACIONALISTA: } \\
\text { Transcendencia de la categoría nacionalista }\end{array}$ & \\
\hline Variables tipo & Código: (25) & Palabras clave \\
\hline El ciudadano & $\begin{array}{l}\text { Il ne faut pas oublier que pour les canadiens anglais } \\
\text { Lucien Bouchard est non seulement un ennemi politique, } \\
\text { mais l'incarnation du mal Pour le Canada anglais... le } \\
\text { Canada anglais connaît très mal nos politiciens. ... Lucien } \\
\text { Bouchard comme autrefois René Levesque ou autres était } \\
\text { connu comme l'incarnation du mal, du nazisme. La per- } \\
\text { ception que les Canadiens anglais, les Américains et les } \\
\text { étrangers en général ont du nationalisme Québécois est } \\
\text { une perception tronquée. Et beaucoup de gens ne nous ont } \\
\text { pas compris et ont véhiculé à notre sujet toutes sortes d'i- } \\
\text { mages, en nous associant, nous les indépendantistes Qué- } \\
\text { bécois, à des mouvements réactionnaires. Ce n'est pas du } \\
\text { tout le cas. Dans le domaine du militantisme presque tous } \\
\text { les poètes étaient carrément indépendantistes. Et l'on a } \\
\text { jamais vu au Québec un poète fédéraliste, un poète qui } \\
\text { chantait les vertus du fédéralisme, on n'en a jamais vu. } \\
\text { Beaucoup de poètes qui militaient pour le Québec libre et } \\
\text { dans ce sens là le mouvement nationaliste n'était pas asso- } \\
\text { cié à une philosophie rétrograde, conservatrice ou repliée } \\
\text { sur elle-même comme le sont souvent les nationalismes } \\
\text { traditionnels comme on en voit en Europe. Moi je ne pen- } \\
\text { se pas que le projet nationaliste puisse répondre à toutes } \\
\text { les aspirations. On se leurre dans un sens et dans l'autre. } \\
\text { Et puis de toute façon si on regarde les réalités actuelles, } \\
\text { c'est la mondialisation. On signe avec le fédéral des } \\
\text { accords sur l'éducation, l'immigration, et puis ca y est on } \\
\text { dit on l'a notre souveraineté Le nationalisme se réclame } \\
\text { de moins en moins de la langue. Mais il y a eu un temps où } \\
\text { la langue était un peu mieux protégée. Ca s'effrite actue- } \\
\text { lle-ment. C'est le gros problème, la langue. Mais je ne } \\
\text { pense pas qu'on puisse réduire le nationa-lisme à ca. Je ne }\end{array}$ & $\begin{array}{l}\text { Dans chaque } \\
\text { culture, il y a } \\
\text { toujours des } \\
\text { gens qui veu- } \\
\text { lent avoir leur } \\
\text { propre } \text { - } \\
\text { dentité, leur } \\
\text { propre } \\
\text { appartenance, } \\
\text { et qui veulent } \\
\text { pas faire par- } \\
\text { tie de l'en- } \\
\text { semble. }\end{array}$ \\
\hline
\end{tabular}




\begin{tabular}{|c|c|c|}
\hline & $\begin{array}{l}\text { pense pas que ce soit le vœu le plus cher que ce soit réduit } \\
\text { à la langue. On pourrait dire on vous donne une protec- } \\
\text { tion suffisante à la langue, alors que ca va bien au-delà de } \\
\text { ca, le nationalisme. maintenant je trouve qu'il n'y a plus } \\
\text { tellement de différence entre les deux partis et il y a une } \\
\text { chose que je trouve au Québec, si on a le choix entre deux } \\
\text { formations politiques au Québec, on a toujours choisi } \\
\text { celle qui présente un leader charismatique. On a été chan- } \\
\text { ceux parce que on en a eus. Même les Québécois ne pou- } \\
\text { vaient pas s'empêcher d'admirer secrètement Pierre Elliot } \\
\text { Trudeau, même si .... Vous savez que les grands nationa- } \\
\text { listes aussi Lucien Bouchard, est marié avec une américai- } \\
\text { ne... René Lesvesque était parfaitement bilingue. il était } \\
\text { correspondant de guerre pour l'armée américaine. Juste- } \\
\text { ment. Nous avons de grands poètes comme Gilles Vigne- } \\
\text { ault qui ont épousé des anglaises. Ce qui prouve une gran- } \\
\text { de ouverture d'esprit chez les nationalistes québécois. } \\
\text { Dans chaque culture, il y a toujours des gens qui veulent } \\
\text { avoir leur propre identité, leur propre appartenance, et qui } \\
\text { veulent pas faire partie de l'ensemble. Sur les îlles britan- } \\
\text { niques, c'est pareil. Ici c'est au Québec. Par contre, il y a } \\
\text { toujorus cette espèce de philosophie tout à fait opposée } \\
\text { qui dit, non, c'est complètement rétrograde de réagir com- } \\
\text { me ça, il faut s'ouvrir au monde. Être nationaliste, c'est } \\
\text { pas correct parce qu'on se referme sur nous-mêmes, on } \\
\text { n'est pas ouvert à l'univers, à tout ce que l'univers peut } \\
\text { nous offrir. C'est des points de vue tellement différents, on } \\
\text { peut en discuter pendant très longtemps, mais c'est com- } \\
\text { me une espèce de clivage. Il y a des points de vue telle- } \\
\text { ment opposés par rapport à ça, qui disent que quand on est } \\
\text { nationaliste, on se replie sur soi-même et le fait de se res- } \\
\text { pecter soi-même, on s'ouvre au monde parce que à partir } \\
\text { du moment où on s'appartient, on peut s'ouvrir vers le } \\
\text { monde avec plus de confiance en soi. D'autres disent que } \\
\text { se refermer sur soi, c'est pas correct parce que on est com- } \\
\text { pletement isolé, on est fermé sur ce qui se passe sur le res- } \\
\text { te de l'univers, alors. }\end{array}$ & \\
\hline $\begin{array}{l}\text { CATEGORÍAS } \\
\text { FORMALES }\end{array}$ & REFERENCIAS AL GÉNERO HUMOR & \\
\hline $\begin{array}{l}\text { Teorías de } \\
\text { la mente }\end{array}$ & Código: (31) & Palabras clave \\
\hline Realidad & $\begin{array}{l}\text { On parle de l'humour dans cette forme de commentaire } \\
\text { politique. Si on rit des sentiments de qui que ce soit, que }\end{array}$ & $\begin{array}{l}\text { S'attaquer à la } \\
\text { grande lai-deur }\end{array}$ \\
\hline
\end{tabular}




\begin{tabular}{|c|c|c|}
\hline & $\begin{array}{l}\text { ce soit de la politique ou d'autres choses, c'est sur que } \\
\text { ça blesse. C'est quand même le caricaturiste qui exagè- } \\
\text { re les traits d'une personne. Aussi bien s'attaquer à la } \\
\text { grande laideur d'un politicien ou à la grosseur d'une } \\
\text { politicienne, ou encore à l'infirmité de Mr Chrétien ou } \\
\text { de M. Bouchard, c'est pas politique finalement. Ils ont } \\
\text { fait une caricature qui était méchante, mais... je ne sais } \\
\text { pas si les canadiens anglais ont beaucoup ri, mais nous } \\
\text { on n'a pas ri. (Oui, mais quand même, parce que c'est } \\
\text { un ennemi politique ) C'est de voir un castor, en train de } \\
\text { tron-çonner une jambe de bois. Ça c'est une image qui } \\
\text { est trop forte. Cela dit, il n'y a personne qui peut mieux } \\
\text { faire que Lucien Bouchard avec sa canne et sa jambe de } \\
\text { bois. Puis maintenant on fait des gags avec sa canne } \\
\text { aussi. Jean Chrétien a une bouche croche. Puis il y a } \\
\text { Claude Ryan avec sa laideur....parce que objective- } \\
\text { ment, il est d'une grande laideur. }\end{array}$ & $\begin{array}{l}\text { d'un po-liticien } \\
\text { ou à la } \\
\text { grosseur d'une } \\
\text { politicienne, } \\
\text { c'est pas } \\
\text { politique } \\
\text { finalement. }\end{array}$ \\
\hline $\begin{array}{l}\text { CATEGORÍAS } \\
\text { FORMALES }\end{array}$ & $\begin{array}{l}\text { CATEGORÍAS DE LA REFERENCIA } \\
\text { NACIONALISTA: } \\
\text { Tensiones (ruptura y continuidad) }\end{array}$ & \\
\hline $\begin{array}{l}\text { Teorías de } \\
\text { la mente }\end{array}$ & Código: (32) & Palabras clave \\
\hline Realidad & $\begin{array}{l}\text { Aussi bien s'attaquer à la grande laideur d'un politicien } \\
\text { ou à la grosseur d'une politicienne, ou encore à l'infir- } \\
\text { mité de Mr Chrétien ou de M. Bouchard, c'est pas poli- } \\
\text { tique finalement. Ils ont fait une caricature qui était } \\
\text { méchante, mais... je ne sais pas si les canadiens anglais } \\
\text { ont beaucoup ri, mais nous on n'a pas ri. (Oui, mais } \\
\text { quand même, parce que c'est un ennemi politique ) } \\
\text { C'est de voir un castor, en train de tron-çonner une jam- } \\
\text { be de bois. Ça c'est une image qui est trop forte. Cela } \\
\text { dit, il n'y a personne qui peut mieux faire que Lucien } \\
\text { Bouchard avec sa canne et sa jambe de bois. Puis main- } \\
\text { tenant on fait des gags avec sa canne aussi. Jean Chré- } \\
\text { tien a une bouche croche. Puis il y a Claude Ryan avec } \\
\text { sa laideur....parce que objectivement, il est d'une gran- } \\
\text { de laideur. Au Québec, l'humour, les humoristes, tant à } \\
\text { la télévision que sur scène, semblent avoir évacué } \\
\text { complètement cette dimension-là. Or, les canadiens } \\
\text { anglais eux sont très critiques à l'égard de leurs élites } \\
\text { politiques. Je dois vous dire qu'ils ont une façon aussi } \\
\text { de traiter la question nationale québécoise, des enjeux, } \\
\text { de Lucien Bouchard, qui vise à nous faire rire. Je suis }\end{array}$ & $\begin{array}{l}\text { Les } \\
\text { anglophones } \\
\text { régardent la } \\
\text { question } \\
\text { nationale } \\
\text { québécoise, les } \\
\text { enjeux de } \\
\text { Lucien } \\
\text { Bouchard, } \\
\text { d'une façon qui } \\
\text { vi-se à nous } \\
\text { faire rire. }\end{array}$ \\
\hline
\end{tabular}




\begin{tabular}{|c|c|c|}
\hline & $\begin{array}{l}\text { Québécois et j'aime bien leur humour parce que c'est un } \\
\text { humour qui est tout aussi décapant. Ils ont une façon de } \\
\text { nous dire qu'ils ne se font pas plus d'illusions à propos } \\
\text { de leurs propres politiciens qu'ils ne vont nourrir de } \\
\text { crainte à l'égard du mouvement nationaliste québécois. }\end{array}$ & \\
\hline $\begin{array}{l}\text { CATEGORÍAS } \\
\text { FORMALES }\end{array}$ & $\begin{array}{l}\text { CATEGORÍAS DE LA REFERENCIA } \\
\text { NACIONALISTA: } \\
\text { Apelación a un origen (tiempo y espacio) }\end{array}$ & \\
\hline $\begin{array}{l}\text { Teorías de } \\
\text { la mente }\end{array}$ & Código: (33) & Palabras clave \\
\hline Realidad & $\begin{array}{l}\text { Pratiquement les francophones depuis la révolution } \\
\text { tranquille, depuis 1960, militent du côté du progrès au } \\
\text { Québec, alors qu'avant la révolution tranquille, avant } \\
\text { 1960, le nationalisme était associé à des valeurs conser- } \\
\text { vatrices, religieuses, un nationalisme pas trop dangereu- } \\
\text { ses qui ne remettait pas en cause le pouvoir, qui n'exige- } \\
\text { ait pas l'indépendance politique. C'est à partir du } \\
\text { moment où la révolution tranquille est arrivée, et un tout } \\
\text { petit peu plus tard, vers la fin des années 60, que les par- } \\
\text { tis indépendantistes se sont associés pour fonder un } \\
\text { mouvement nationaliste qui n'ait plus dans son discours } \\
\text { une dimension religieuse, mais qui avait une vision } \\
\text { moderne du nationalisme, et beaucoup d'entre eux } \\
\text { étaient des gens de gauche. Et le nationalisme était véhi- } \\
\text { culé non seulement par les partis nationalistes, mais aus- } \\
\text { si par les centrales syndicales. }\end{array}$ & $\begin{array}{l}\text { Avant la ré- } \\
\text { volution } \\
\text { tranquille, } \\
\text { avant } 1960, \text { le } \\
\text { nationalisme é- } \\
\text { tait associé à } \\
\text { des valeurs } \\
\text { conservatrices }\end{array}$ \\
\hline $\begin{array}{l}\text { CATEGORÍAS } \\
\text { FORMALES }\end{array}$ & $\begin{array}{l}\text { CATEGORÍAS DE LA REFERENCIA } \\
\text { NACIONALISTA: } \\
\text { Manifestaciones culturales de la diferencia }\end{array}$ & \\
\hline $\begin{array}{l}\text { Teorías de } \\
\text { la mente }\end{array}$ & Código: (34) & Palabras clave \\
\hline Realidad & $\begin{array}{l}\text { Beaucoup de poètes ont parlé par exemple des nationa- } \\
\text { listes africains dans les années } 60 \text {. Les pays d'Afrique } \\
\text { ne réclamaient pas l'indépendance parce que leurs ido- } \\
\text { les étaient des réactionnaites, au contraire. Nous c'était } \\
\text { pareil sauf que c'était toutes proportions gardées, on } \\
\text { était quand même en Amérique du Nord, on n'avait pas } \\
\text { à sortir d'un système d'occupation réelle par les colonns }\end{array}$ & $\begin{array}{l}\text { Beaucoup de } \\
\text { gens ne nous } \\
\text { ont pas compris } \\
\text { et ont véhiculé } \\
\text { à notre sujet } \\
\text { toutes sortes } \\
\text { d'images, en }\end{array}$ \\
\hline
\end{tabular}




\begin{tabular}{|c|c|c|}
\hline & $\begin{array}{l}\text { oui et non selon les points de vue. On était quand même } \\
\text { dans un système démocratique depuis longtemps, toutes } \\
\text { proportions gardées. Le mouvement s'inscrivait dans } \\
\text { une mouvance internationale dans les années 60, celui } \\
\text { de l'affranchissement. Et beaucoup de gens ne nous ont } \\
\text { pas compris et ont véhiculé à notre sujet toutes sortes } \\
\text { d'images, en nous associant, nous les indépendantistes } \\
\text { Québé-cois, à des mouvements réactionnaires. Ce n'est } \\
\text { pas du tout le cas. Les Québecois qui sont bilingues, } \\
\text { c'est à Montréal qui est la plaque tournante du Canada. } \\
\text { Les Anglophones, ils n'ont pas besoin de parler } \\
\text { français, ils sont chez eux. Partout où ils sont ils sont } \\
\text { chez eux. C'est comme ça. Les Ontariens qui habitent à } \\
\text { côté, ils ne parlent pas français. Même quand ils vien- } \\
\text { nent ici au Québec, ils ne s'efforcent pas de parler } \\
\text { français. Ils vont juste parler anglais., et ils vont se faire } \\
\text { servir en anglais dans les restaurants. À Montréal, tu n'a } \\
\text { pas le choix. Dans les restaurants, les maçasins de Mon- } \\
\text { tréal il y en a qui ne parlent même pas français. Puis ils } \\
\text { vont te servir en anglais. Moi j'étais en recherche d'em- } \\
\text { ploi à Montréal. La première chose qu'ils me deman- } \\
\text { dent c'est est-ce que tu es bilingue? Je baragouine l'an- } \\
\text { glais. Je suis capable de comprendre. Mais de là à tenir } \\
\text { une conversation en anglais, Nenni. Puis dire que au } \\
\text { Québec, la loi 101, la langue française.. }\end{array}$ & $\begin{array}{l}\text { nous associant, } \\
\text { nous les } \\
\text { indépendantiste } \\
\text { s Québé-cois, à } \\
\text { des } \\
\text { mouvements } \\
\text { réactionnaires. } \\
\text { Ce n'est pas du } \\
\text { tout le cas. }\end{array}$ \\
\hline $\begin{array}{l}\text { CATEGORÍAS } \\
\text { FORMALES }\end{array}$ & $\begin{array}{l}\text { CATEGORÍAS DE LA REFERENCIA } \\
\text { NACIONALISTA: } \\
\text { Transcendencia de la categoría nacionalista }\end{array}$ & \\
\hline $\begin{array}{l}\text { Teorías de } \\
\text { la mente }\end{array}$ & Código: (35) & Palabras clave \\
\hline Realidad & $\begin{array}{l}\text { Pour eux (les non Québecois) le fait français c'est la } \\
\text { France. Ils nous appellent frog parce que les français } \\
\text { mangent des grenouilles alors qu'ici on en mange même } \\
\text { pas de grenouilles. Ils confondent tout. Bill Clinton } \\
\text { avait dit quand il était venu à Ottawa : je connais bien la } \\
\text { France, j'ai visité Montréal. Il y a énormément de fran- } \\
\text { cophones au Québec qui ne sont pas nationalistes. On } \\
\text { ne peut pas dire il y a les francophones et il y a les } \\
\text { anglophones puis automatiquement ça résout le problè- } \\
\text { me. S'il n'y a pratiquement pas d'anglophones qui sont } \\
\text { nationalistes, il y a quand même de nombreux francop- } \\
\text { hones qui ne sont pas nationalistes, qui se reconnaissent } \\
\text { comme étant distincts des anglais mais qui ne sont pas }\end{array}$ & $\begin{array}{l}\text { Quand on est } \\
\text { tous } \\
\text { nationalistes, il } \\
\text { n'y a pas de } \\
\text { problème. Au } \\
\text { Quèbec, la } \\
\text { plupart des hu- } \\
\text { moristes sont } \\
\text { nationalistes. Il } \\
\text { n'y a pas d' hu- } \\
\text { mour } \\
\text { antinationaliste } \\
\text { au Quèbec. }\end{array}$ \\
\hline
\end{tabular}




\begin{tabular}{|c|c|c|}
\hline & $\begin{array}{l}\text { nationalistes. Quand on est tous nationalistes, il n'y a } \\
\text { pas deproblème. Remarquez aussi que au Quèbec, la } \\
\text { plupart des humoristes sont nationalistes. Il n'y a pasd'- } \\
\text { humour antinationalistes au Quèbec. }\end{array}$ & \\
\hline $\begin{array}{l}\text { CATEGORÍAS } \\
\text { FORMALES }\end{array}$ & REFERENCIAS AL GÉNERO HUMOR & \\
\hline $\begin{array}{l}\text { Teorías de la } \\
\text { mente }\end{array}$ & Código: (41) & Palabras clave \\
\hline Deseo & & \\
\hline $\begin{array}{l}\text { CATEGORÍAS } \\
\text { FORMALES }\end{array}$ & $\begin{array}{l}\text { CATEGORÍAS DE LA REFERENCIA } \\
\text { NACIONALISTA: } \\
\text { Tensiones (ruptura y continuidad) }\end{array}$ & \\
\hline $\begin{array}{l}\text { Teorías de } \\
\text { la mente }\end{array}$ & Código: (42) & Palabras clave \\
\hline Deseo & $\begin{array}{l}\text { Il y a comme une idée de projet nationaliste c'est beau } \\
\text { l'idée de protéger sa langue et sa culture, mais en même } \\
\text { temps il faut aussi trouver un moyen de proclamer sa } \\
\text { spécificité dans un projet de société. Il faut dire que le } \\
\text { genre de réforme que nous on voudrait voir arriver dans } \\
\text { les lois, dans les institutions, dans ce qui est attribué à } \\
\text { chaque province, si on l'obtenait, il y a d'autres provin- } \\
\text { ces qui aimeraient l'avoir aussi. Il y a des provinces } \\
\text { comme la Colombie britannique et l'Ontario qui se } \\
\text { manifestent rarement. Dernièrement peut-être la } \\
\text { Colombie britannique, mais qui aimeraient bien avoir } \\
\text { certains changements aussi. Mais ils nous laissent l'o- } \\
\text { dieux d'aller de l'avant et d'obtenir ces changements -là } \\
\text { qui soit plus un partenariat. Je suis convaincue que la } \\
\text { majorité des provinces seraient bien heureuses de se } \\
\text { retrouver dans ce fédéralisme-là qui seraient moins cen- } \\
\text { tralisateur, qui leur donneraient pleins pouvoirs. C'est } \\
\text { toujours le Québec qui demande ces changements-là. } \\
\text { Les plus riches appuient beaucoup plus au Canada une } \\
\text { certaine souveraineté Pour des raisons économoiques. } \\
\text { Parce que le fédéral il les bloque, alors eux autres ils } \\
\text { veulent se séparer pour être autonomes, et garder leurs } \\
\text { richesses. Eux autres aussi vivent la même chose. Au } \\
\text { point de vue culturel, il y en a aussi qui sont insatisfaits. }\end{array}$ & $\begin{array}{l}\text { Il y a comme } \\
\text { une idée de } \\
\text { projet } \\
\text { nationaliste } \\
\text { c'est beau } \\
\text { l'idée de } \\
\text { protéger sa } \\
\text { langue et sa } \\
\text { culture, mais en } \\
\text { mê-me temps il } \\
\text { faut aussi } \\
\text { trouver un } \\
\text { moyen de } \\
\text { proclamer sa } \\
\text { spécificité dans } \\
\text { un projet de } \\
\text { société. }\end{array}$ \\
\hline
\end{tabular}




\begin{tabular}{|c|c|c|}
\hline & $\begin{array}{l}\text { J'écoutais il n'y a pas longtemps Mike Harris. Il disait } \\
\text { que les Maritimes sont comme un assisté social qui gag- } \\
\text { ne à la loterie mais qui veut garder son chèque de BS } \\
\text { (Bien-être social) C'est comme le gars qui porte à la fois } \\
\text { des bretelles puis une ceinture. Puis il dit que les Pro- } \\
\text { vinces maritimes réclament un partage plus équitable de } \\
\text { la richesse, qui vient de l'Alberta, de l'Ontario, de la } \\
\text { Colombie britannique, du Québec Oui, on est la plus } \\
\text { riche des provinces pauvres et la plus pauvre des pro- } \\
\text { vinces riches. Mike Harris a dit ce que Terre Neuve, } \\
\text { demande, c'est comme una assisté social qui a un } \\
\text { emploi de } 100 \text { mille dollars pas anne et qui veut conti- } \\
\text { nuer de toucher son chèque d'assistance sociale. }\end{array}$ & \\
\hline $\begin{array}{l}\text { CATEGORÍAS } \\
\text { FORMALES }\end{array}$ & $\begin{array}{l}\text { CATEGORÍAS DE LA REFERENCIA } \\
\text { NACIONALISTA: } \\
\text { Apelación a un origen (tiempo y espacio) }\end{array}$ & \\
\hline $\begin{array}{l}\text { Teorías de } \\
\text { la mente }\end{array}$ & Código: (43) & Palabras clave \\
\hline Deseo & & \\
\hline $\begin{array}{l}\text { CATEGORÍAS } \\
\text { FORMALES }\end{array}$ & $\begin{array}{l}\text { CATEGORÍAS DE LA REFERENCIA } \\
\text { NACIONALISTA: } \\
\text { Manifestaciones culturales de la diferencia }\end{array}$ & \\
\hline $\begin{array}{l}\text { Teorías de } \\
\text { la mente }\end{array}$ & Código: (44) & Palabras clave \\
\hline Deseo & $\begin{array}{l}\text { À un certain moment il y a une limite à ne pas franchir: } \\
\text { Parler de la disgrâce de quelqu'un, ou d'un handicap } \\
\text { quelconque (L. Bouchard) Si on trouve ça horrible, on } \\
\text { devrait aussi dénoncer tous les caricaturistes qui ont } \\
\text { dessiné Jean Chrétien en mettant l'accent sur sa bouche } \\
\text { croche ou quelque chose comme ça. }\end{array}$ & $\begin{array}{l}\text { On devrait } \\
\text { dénoncer tous } \\
\text { les } \\
\text { caricaturistes } \\
\text { qui ont dessiné } \\
\text { Jean Chrétien } \\
\text { en mettant } \\
\text { l'accent sur sa } \\
\text { bouche croche } \\
\text { ou quelque } \\
\text { chose comme } \\
\text { ça. }\end{array}$ \\
\hline
\end{tabular}




\begin{tabular}{|c|c|c|}
\hline $\begin{array}{l}\text { CATEGORÍAS } \\
\text { FORMALES }\end{array}$ & $\begin{array}{l}\text { CATEGORÍAS DE LA REFERENCIA } \\
\text { NACIONALISTA: } \\
\text { Transcendencia de la categoría nacionalista }\end{array}$ & \\
\hline $\begin{array}{l}\text { Teorías de } \\
\text { la mente }\end{array}$ & Código: (45) & Palabras clave \\
\hline Deseo & $\begin{array}{l}\text { L'identité Québécois est une identité qui se construit } \\
\text { par rapport à l'identité Anglophones ou c'est une iden- } \\
\text { tité qui va plus loin?. Ca se construisait plutôt par rap- } \\
\text { port à l'identité anglophone parce que c'est une façon } \\
\text { de nous définir par rapport à notre voisin. Mais de plus } \\
\text { en plus je pense qu'on essaye de nous définir par rap- } \\
\text { port au monde entier. Évidemment ça parait un peu } \\
\text { problématique parce que par rapport au monde entier } \\
\text { on est une poussière: } 7 \text { millions d'individus. Mais on } \\
\text { voudrait quand même... je crois qu'il y un discours } \\
\text { nationaliste qui veut qu'on soit reconnu par le monde } \\
\text { entier en tant que peuple. Que la France cesse de nous } \\
\text { considérer comme un petit territoire d'outre-mer, mais } \\
\text { nous considère comme un peuple, une nation avec ses } \\
\text { particularités et une de ces particularités c'est de parler } \\
\text { français, pas forcément comme on le parle en France. } \\
\text { Le Québec s'est appauvré progressivement depuis } \\
\text { quelques années Si on n'était pas dans la confédéra- } \\
\text { tion, les choses auraient peut-être été différentes. Mais } \\
\text { on est défavorisés. On nous défavorise au profit de } \\
\text { l'Ontario.. L'économiste de Terre Neuve disait : les } \\
\text { dicisions sont prises à Ottawa, puis les retombies } \\
\text { importantes se retrouvent le plus souvent en Ontario. } \\
\text { À Terre Neuve, on ne voit que la lueur des retombies. } \\
\text { L'Aberta fait bien grâce à son pétrole. Ils n'ont prati- } \\
\text { quement pas d'imptôs, ils n'ont pas de taxe provincia- } \\
\text { le, la TPS (Taxe sur les produits et services). }\end{array}$ & $\begin{array}{l}\text { Ça se } \\
\text { construisait } \\
\text { plutôt par } \\
\text { rapport à } \\
\text { l'identité an- } \\
\text { glophone } \\
\text { puisque que } \\
\text { c'est une fa-çon } \\
\text { de nous définir } \\
\text { par rapport à } \\
\text { no-tre voisin. } \\
\text { Mais de plus en } \\
\text { plus on essaye } \\
\text { de nous définir } \\
\text { par rapport au } \\
\text { monde en-tier. }\end{array}$ \\
\hline $\begin{array}{l}\text { CATEGORÍAS } \\
\text { FORMALES }\end{array}$ & REFERENCIAS AL GÉNERO HUMOR & \\
\hline $\begin{array}{l}\text { Teorías de } \\
\text { la mente }\end{array}$ & Código: (51) & Palabras clave \\
\hline Ficción & & \\
\hline
\end{tabular}




\begin{tabular}{|c|c|c|}
\hline $\begin{array}{l}\text { CATEGORÍAS } \\
\text { FORMALES }\end{array}$ & $\begin{array}{l}\text { CATEGORÍAS DE LA REFERENCIA } \\
\text { NACIONALISTA: } \\
\text { Tensiones (ruptura y continuidad) }\end{array}$ & \\
\hline $\begin{array}{l}\text { Teorías de } \\
\text { la mente }\end{array}$ & Código: (52) & Palabras clave \\
\hline Ficción & & \\
\hline $\begin{array}{l}\text { CATEGORÍAS } \\
\text { FORMALES }\end{array}$ & $\begin{array}{l}\text { CATEGORÍAS DE LA REFERENCIA } \\
\text { NACIONALISTA: } \\
\text { Apelación a un origen (tiempo y espacio) }\end{array}$ & \\
\hline $\begin{array}{l}\text { Teorías de } \\
\text { la mente }\end{array}$ & Código: (53) & Palabras clave \\
\hline Ficción & & \\
\hline $\begin{array}{l}\text { CATEGORÍAS } \\
\text { FORMALES }\end{array}$ & $\begin{array}{l}\text { CATEGORÍAS DE LA REFERENCIA } \\
\text { NACIONALISTA: } \\
\text { Manifestaciones culturales de la diferencia }\end{array}$ & \\
\hline $\begin{array}{l}\text { Teorías de } \\
\text { la mente }\end{array}$ & Código: (54) & Palabras clave \\
\hline Ficción & & \\
\hline $\begin{array}{l}\text { CATEGORÍAS } \\
\text { FORMALES }\end{array}$ & $\begin{array}{l}\text { CATEGORÍAS DE LA REFERENCIA } \\
\text { NACIONALISTA: } \\
\text { Transcendencia de la categoría nacionalista }\end{array}$ & \\
\hline $\begin{array}{l}\text { Teorías de } \\
\text { la mente }\end{array}$ & Código: (55) & Palabras clave \\
\hline Ficción & & \\
\hline
\end{tabular}




\begin{tabular}{|c|c|c|}
\hline $\begin{array}{l}\text { CATEGORÍAS } \\
\text { FORMALES }\end{array}$ & REFERENCIAS AL GÉNERO HUMOR & \\
\hline $\begin{array}{l}\text { Modalidad } \\
\text { de la expresión }\end{array}$ & Código: (61) & Palabras clave \\
\hline Aléthica & $\begin{array}{l}\text { Ça (le rire) doit les blesser (aux politiciens). Ça (l'hu- } \\
\text { mour) blesse souvent les politiques, les personnes qui } \\
\text { ont de grandes convictions. Le ridicule d'un politi- } \\
\text { cien, c'est un personnage public après tout, il fait de } \\
\text { la politique. Non, ça en principe ça blesse mais à mon } \\
\text { avis ce n'est pas politique. Ça blesse le personnage } \\
\text { politique, ca ne porte pas sur ses sentiments politi- } \\
\text { ques, sur sa façon de faire la politique. C'est d'une } \\
\text { grande méchanceté. Aussi bien s'attaquer à la grande } \\
\text { laideur d'un politicien ou à la grosseur d'une politi- } \\
\text { cienne, ou encore à l'infirmité de Mr. Chrétien ou de } \\
\text { M. Bouchard, c'est pas politique finalement. On par- } \\
\text { le de l'humour dans cette forme de commentaire poli- } \\
\text { tique. Si on rit des sentiments de qui que ce soit, que } \\
\text { ce soit de la politique ou d'autres choses, c'est sur } \\
\text { que ça blesse. C'est quand même le caricaturiste qui } \\
\text { exagère les traits d'une personne. Il y en a peut-être } \\
\text { qui lisent les éditoriaux, mais tout le monde regarde } \\
\text { les caricatu-res. Ça dure le temps du rire, tout simple- } \\
\text { ment. Si on rit des sentiments de qui que ce soit, que } \\
\text { ce soit de la politique ou d'autres choses, c'est sur } \\
\text { que ça blesse. Quelqu'un qui fait une caricature pour } \\
\text { blesser, ridiculiser quelqu'un ou quelque chose, ce } \\
\text { que l'on croit ou ce que l'on aime, une conviction, ça } \\
\text { blesse momentanément. Mais si on se rend compte } \\
\text { que la personne qui veut faire de l'humour ou qui } \\
\text { veut faire la blague avec la caricature, ils sont au cou- } \\
\text { rant, qu'ils sont renseignés, c'est plus acceptable que } \\
\text { s'ils étaient ignorants ou comme ca a été longtemps } \\
\text { ou comme c'est encore dans une gros-se partie du } \\
\text { Canada anglais. Ce que font les caricaturistes, c'est } \\
\text { de dénoncer la démagogie (des politiciens). Je ne } \\
\text { crois pas que l'humour dans la caricature ait besoin } \\
\text { d'être blessant pour porter. Les caricaturistes, cher- } \\
\text { chent à faire ça (ridiculiser) systématiquement. Mais } \\
\text { il arrive aussi au caricaturiste de faire quelque chose } \\
\text { de plus humain, de moins dérangeant. Si par exemple } \\
\text { il y a un politicien ou un columnist qui meurt, il dési- } \\
\text { re lui rendre hommage. }\end{array}$ & $\begin{array}{l}\text { Si on rit des } \\
\text { sentiments de } \\
\text { qui que ce soit, } \\
\text { que ce soit de } \\
\text { la politique ou } \\
\text { d'autres } \\
\text { choses, c'est } \\
\text { sur que ça } \\
\text { blesse. }\end{array}$ \\
\hline
\end{tabular}




\begin{tabular}{|c|c|c|}
\hline $\begin{array}{l}\text { CATEGORÍAS } \\
\text { FORMALES }\end{array}$ & $\begin{array}{l}\text { CATEGORÍAS DE LA REFERENCIA } \\
\text { NACIONALISTA: } \\
\text { Tensiones (ruptura y continuidad) }\end{array}$ & \\
\hline $\begin{array}{l}\text { Modalidad } \\
\text { de la expresión }\end{array}$ & Código: (62) & Palabras clave \\
\hline Aléthica & $\begin{array}{l}\text { Tout ce qu'on a pu faire avec le français (comme lan- } \\
\text { gue) c'est bien mais il y a toute une série d'autres } \\
\text { aspects du quotidien qu'on ne peut pas réduire à la lan- } \\
\text { gue. La dimension politique, économique, qui ne dev- } \\
\text { raient pas être associées uniquement À LA LANGUE. } \\
\text { Avec la richesse que l'Alberta a, ils ont des tas de rai- } \\
\text { sons de se séparer. Ou en tous cas de séparer leur écono- } \\
\text { mie pour avoir plus de pouvoirs. En tout cas ce ne serait } \\
\text { pas surprenant que ce soit eux qui l'obtiennent en pre- } \\
\text { miers, justement parce qu'ils sont tellement riches que } \\
\text { ca leur donne le pouvoir de négocier. }\end{array}$ & $\begin{array}{l}\text { Avec la ri- } \\
\text { chesse que } \\
\text { l'Alberta a, ils } \\
\text { ont des tas de } \\
\text { raisons de se } \\
\text { séparer }\end{array}$ \\
\hline $\begin{array}{l}\text { CATEGORÍAS } \\
\text { FORMALES }\end{array}$ & $\begin{array}{l}\text { CATEGORÍAS DE LA REFERENCIA } \\
\text { NACIONALISTA: } \\
\text { Apelación a un origen (tiempo y espacio) }\end{array}$ & \\
\hline $\begin{array}{l}\text { Modalidad } \\
\text { de la expresión }\end{array}$ & Código: (63) & Palabras clave \\
\hline Aléthica & $\begin{array}{l}\text { Il faut regarder ce qui s'est passé au Manitoba. C'est } \\
\text { presque un génocide culturel qui s'est fait au début du } \\
\text { siècle en fermant les écoles. À cause du passage de Tru- } \\
\text { deau, dans la constitution, on a forcé le gouvernement } \\
\text { du Manitoba de traduire toutes ses lois en français. } \\
\text { C'est quand même important. Je sais bien que tu vas } \\
\text { me dire que ca ne correspond pas à la réalité, mais au } \\
\text { niveau des institutions, c'est important. Quand j'ai } \\
\text { apporté cet exemple, c'est pour te montrer de quelle } \\
\text { façon souvent peuvent raisonner les Québécois. Histo- } \\
\text { riquement, il faut reconnaître quand même le rôle du } \\
\text { parti libéral. C'est le parti libéral qui a fait la révolution } \\
\text { tranquille ici après une période de conservatisme, de } \\
\text { droite avec l'Union nationale. Tous les changements } \\
\text { majeurs qu'il y a eus dans la révolution tranquille, la } \\
\text { santé, l'éducation, la nationalisation de l'électricité } \\
\text { dans les années } 60 \text {. Avec René Levesque. Il était minis- } \\
\text { tre des Ressources naturelles, c'est lui qui a privatisé } \\
\text { l'électricité C'est ça. Ça a quand même été fait par le } \\
\text { parti libéral. Plusieurs leaders du parti libéral ont quitté }\end{array}$ & $\begin{array}{l}\text { Il faut regarder } \\
\text { ce qui s'est } \\
\text { passé. C'est } \\
\text { presque un } \\
\text { génocide } \\
\text { culturel qui } \\
\text { s'est fait au } \\
\text { début du siè-cle } \\
\text { en fer-mant les } \\
\text { éco-les au } \\
\text { Manitoba. } \\
\text { Trudeau, après } \\
\text { a forcéle gou- } \\
\text { vernment du } \\
\text { Manitoba de } \\
\text { traduire tou-tes } \\
\text { ses lois en } \\
\text { français. }\end{array}$ \\
\hline
\end{tabular}




\begin{tabular}{|c|c|c|}
\hline & $\begin{array}{l}\text { ce parti et ont fondé le parti Québécois et depuis les } \\
\text { années } 70 \text {, le parti libéral est devenu un parti plus à } \\
\text { droite, un parti au service de la grande bourgeoisie et } \\
\text { du capital. Tandis que le parti québécois était un parti } \\
\text { au départ socio-démocrate, près de la petite bourgeoisie } \\
\text { et de la bourgeoisie montante. }\end{array}$ & \\
\hline $\begin{array}{l}\text { CATEGORÍAS } \\
\text { FORMALES }\end{array}$ & $\begin{array}{l}\text { CATEGORÍAS DE LA REFERENCIA } \\
\text { NACIONALISTA: } \\
\text { Manifestaciones culturales de la diferencia }\end{array}$ & \\
\hline $\begin{array}{l}\text { Modalidad } \\
\text { de la expresión }\end{array}$ & Código: (64) & Palabras clave \\
\hline Aléthica & $\begin{array}{l}\text { La perception que les Canadiens anglais, les Améri- } \\
\text { cains et les étrangers en général ont du nationalisme } \\
\text { Québécois est une perception tronquée. Les Cana- } \\
\text { diens anglais ont depuis quelques temps à la TV des } \\
\text { émissions d'humour. C'est très étonnant parce que ce } \\
\text { sont des émissions qui visent particulièrement les } \\
\text { politiciens, ce qui n'existe plus ici au Québec. Beau- } \\
\text { coup de poètes ont parlé par exemple des nationalistes } \\
\text { africains dans les années } 60 \text {. les pays d'Afrique ne } \\
\text { réclamaient pas l'indépendance parce que leurs idoles } \\
\text { étaient des réactionnaites, au contraire. Nous c'était } \\
\text { pareil sauf que c'était toutes proportions gardées, on } \\
\text { était quand même en Amérique du Nord, on n'avait } \\
\text { pas à sortir d'un système d'occupation réelle par les } \\
\text { colonns oui et non selon les points de vue. On était } \\
\text { quand même dans un système démocratique depuis } \\
\text { longtemps, toutes proportions gardées. Le mouvement } \\
\text { s'inscrivait dans une mouvance inter-nationale dans } \\
\text { les années } 60 \text {, celui de l'affranchissement. Et beau- } \\
\text { coup de gens ne nous ont pas compris et ont véhiculé } \\
\text { à notre sujet toutes sortes d'images, en nous associant, } \\
\text { nous les indépendantistes Québécois, à des mouve- } \\
\text { ments réactionnaires. Ce n'est pas du tout le cas. Et } \\
\text { l'on a jamais vu au Québec un poète fédéraliste, un } \\
\text { poète qui chantait les vertus du fédéralisme, on n'en a } \\
\text { jamais vu. Beaucoup de poètes qui militaient pour le } \\
\text { Québec libre et dans ce sens là le mouvement nationa- } \\
\text { liste n'était pas associé à une philosophie rétrograde, } \\
\text { conservatrice ou repliée sur elle-même comme le sont } \\
\text { souvent les nationalismes traditionnels comme on en } \\
\text { voit en Europe. }\end{array}$ & $\begin{array}{l}\text { La perception } \\
\text { que les } \\
\text { Canadiens } \\
\text { anglais, les } \\
\text { Américains et } \\
\text { les étrangers en } \\
\text { général ont du } \\
\text { nationalisme } \\
\text { Québécois est } \\
\text { une perception } \\
\text { tronquée. }\end{array}$ \\
\hline
\end{tabular}




\begin{tabular}{|c|c|c|}
\hline $\begin{array}{l}\text { CATEGORÍAS } \\
\text { FORMALES }\end{array}$ & $\begin{array}{l}\text { CATEGORÍAS DE LA REFERENCIA } \\
\text { NACIONALISTA: } \\
\text { Transcendencia de la categoría nacionalista }\end{array}$ & \\
\hline $\begin{array}{l}\text { Modalidad } \\
\text { de la expresión }\end{array}$ & Código: (65) & Palabras clave \\
\hline Aléthica & $\begin{array}{l}\text { Que la France cesse de nous considérer comme un petit } \\
\text { territoire d'outre-mer, mais nous considère comme un } \\
\text { peuple, une nation avec ses particularités et une de ces } \\
\text { particularités c'est de parler français, pas forcément } \\
\text { comme on le parle en France. Et il y a d'autres particu- } \\
\text { larités aussi. Et c'est cela que les indépendan-tistes } \\
\text { Québécois voudraient voir reconnaître. Maintenant les } \\
\text { Québécois se sentent assez forts.En arrière d'eux il y a } \\
\text { des réalisations qui leur permettent de se dire : on peut } \\
\text { se mesurer à n'importe qui dans le monde, au niveau } \\
\text { économique, au niveau des technologies ... Ce n'est pas } \\
\text { simplement nous qui les reconnaissons ces accom-plis- } \\
\text { sements-là. Mais ça a été reconnu de l'extérieur comme } \\
\text { quelque chose qui se compare au reste du monde. Il y a } \\
\text { aussi l'aspect du nationalisme qui ne peut pas vraiment } \\
\text { s'identifier ou se rapporter à la langue. Je suis allée en } \\
\text { France pour la première fois. J'ai eu un choc culturel.En } \\
\text { pleine face. Ce n'est pas mon pays, je ne voudrais } \\
\text { jamais vivre là. J'ai été subjugée, assommée par Paris. J } \\
\text { 'ai été assomée par cette ville européenne. Et pourtant, } \\
\text { des amis nous ont accueillis à bras ouverts, ils nous ont } \\
\text { tout donné, et pourtant, je leur ai dit: vous savez, je suis } \\
\text { une nord américaine. Jamais je ne pourrais vivre en } \\
\text { France.Je vivrai en France en vacances, mais c'est ici } \\
\text { chez nous. Je vivrai plus en France qu'aux USA, mais je } \\
\text { ne passerai pas ma vie en France. }\end{array}$ & $\begin{array}{l}\text { Que la France } \\
\text { cesse de nous } \\
\text { considérer } \\
\text { comme un petit } \\
\text { territoire } \\
\text { d'outre-mer, } \\
\text { mais é-tant un } \\
\text { peu-ple, une } \\
\text { nation avec ses } \\
\text { particularités et } \\
\text { une de ces } \\
\text { particularités } \\
\text { c'est de parler } \\
\text { français, pas } \\
\text { forcment } \\
\text { comme on le } \\
\text { parle en } \\
\text { France. }\end{array}$ \\
\hline $\begin{array}{l}\text { CATEGORÍAS } \\
\text { FORMALES }\end{array}$ & REFERENCIAS AL GÉNERO HUMOR & \\
\hline $\begin{array}{l}\text { Modalidad } \\
\text { de la expresión }\end{array}$ & Código: (71) & Palabras clave \\
\hline Epistémica & $\begin{array}{l}\text { Il y en a peut-être qui lisent les éditoriaux, mais tout le } \\
\text { monde regarde les caricatures. Ça dure le temps du rire, } \\
\text { tout simplement. Si on rit des sentiments de qui que ce } \\
\text { soit, que ce soit de la politique ou d'autres choses, c'est } \\
\text { sur que ça blesse. Quelqu'un qui fait une caricature pour } \\
\text { blesser, ridiculiser quelqu'un ou quelque chose, ce que }\end{array}$ & $\begin{array}{l}\text { C'est moins } \\
\text { acceptable faire } \\
\text { de l'hu-mour si } \\
\text { l'on est } \\
\text { ignorant } \\
\text { comme ca a été }\end{array}$ \\
\hline
\end{tabular}




\begin{tabular}{|c|c|c|}
\hline & $\begin{array}{l}\text { l'on croit ou ce que l'on aime, une conviction, ça blesse } \\
\text { momentanément. Mais si on se rend compte que la per- } \\
\text { sonne qui veut faire de l'humour ou qui veut faire la bla- } \\
\text { gue avec la caricature, ils sont au courant, qu'ils sont } \\
\text { renseignés, c'est plus acceptable que s'ils étaient igno- } \\
\text { rants ou comme ca a été longtemps ou comme c'est } \\
\text { encore dans une grosse partie du Canada anglais. }\end{array}$ & $\begin{array}{l}\text { longtemps dans } \\
\text { une grosse } \\
\text { partie du } \\
\text { Canada } \\
\text { anglais. }\end{array}$ \\
\hline $\begin{array}{l}\text { CATEGORÍAS } \\
\text { FORMALES }\end{array}$ & $\begin{array}{l}\text { CATEGORÍAS DE LA REFERENCIA } \\
\text { NACIONALISTA: } \\
\text { Tensiones (ruptura y continuidad) }\end{array}$ & \\
\hline $\begin{array}{l}\text { Modalidad } \\
\text { de la expresión }\end{array}$ & Código: (72) & Palabras clave \\
\hline Epistémica & $\begin{array}{l}\text { L'identité, après la conquête, elle était menacée après } \\
\text { les institutions anglaises. Le clergé a joué un rôle impor- } \\
\text { tant dans la maintien d'une certaine culture française au } \\
\text { Canada, mais c'est vrai qu'il y a eu ... je peux juste fai- } \\
\text { re une parenthèse, par exemple avec le FLQ (Front de } \\
\text { Libération du Québec), il y avait cette composante-là. Si } \\
\text { on lit les discours felquistes, il y a d'abord une idéologie } \\
\text { communiste. Il s'agissait de libérer le peuple Québécois } \\
\text { qui par hasard était exploité par un patron anglais. Alors } \\
\text { il y avait comme une confusion. Il y avait un discours } \\
\text { nationaliste qui se superposait avec un discours de libé- } \\
\text { ration prolétarienne et c'est vrai que peut-être ça a joué } \\
\text { là. Il y a eu une recherche d'identité, une opposition à } \\
\text { l'envahisseur anglais, mais je crois qu'on a passé ce } \\
\text { cap. Je suis convaincue que la majorité des provinces } \\
\text { seraient bien heureuses de se retrouver dans ce fédéra- } \\
\text { lisme-là qui seraient moins centralisateur, qui leur don- } \\
\text { neraient pleins pouvoirs. C'est toujours le Québec qui } \\
\text { demande ces changements-là. Si on fait abstraction des } \\
\text { revendications traditionnelles du Québec, c'est-à-dire la } \\
\text { culture, l'éducation et l'immigration, les griefs des } \\
\text { autres provinces, c'est les mêmes. On voit que le gou- } \\
\text { vernement fédéral est centralisateur et plus les provin- } \\
\text { ces s'enrichissent, comme la Colombie britannique à } \\
\text { cause de Hong Kong, plus on voit les velléités séces- } \\
\text { sionnistes. Et c'est à se demander si finalement le Qué- } \\
\text { bec ne sera pas la troisième province à se séparer du } \\
\text { Canada. Regarde l'Alberta. Je pense qu'ils (le 'parti } \\
\text { Liberal) n'ont pas de pensée politique. Ils vont au gré du } \\
\text { vent. Jean Charet n'a aucune initiative. Le pauvre, il } \\
\text { s'est fait truander par le fédéral il est en travers de l'é- }\end{array}$ & $\begin{array}{l}\text { Si on fait abs- } \\
\text { traction des } \\
\text { revendictions } \\
\text { traditionelles } \\
\text { du Québec, } \\
\text { c'est-à-dire la } \\
\text { culture, l'é- } \\
\text { ducation et } \\
\text { l'immigrtion, } \\
\text { les griefs des } \\
\text { autres } \\
\text { provinces, c'est } \\
\text { les mêmes. }\end{array}$ \\
\hline
\end{tabular}




\begin{tabular}{|c|c|c|}
\hline & $\begin{array}{l}\text { corce, constamment. On se fait faire des coups de Jar- } \\
\text { nac, constamment, par Stéphane Dion. Jean Charet est } \\
\text { devenu comme une espèce de succursale du parti libé-- } \\
\text { ral. Moi je ne pense pas que nous ayons besoin de nous } \\
\text { séparer du Canada. Sauf que ca change pas. Les } \\
\text { Anglophones n'ont jamais voulu du fédéralisme depuis } \\
\text { 1867. Puis nous on a toujours voulu collaborer, puis } \\
\text { c'est pourquoi on a instauré le fédéralisme. En bout de } \\
\text { ligne au lieu de l'amiliorer, ils l'ont centralisé avec l'ai- } \\
\text { de de la cour supreme d'ailleurs. Les imptôs, c'est le } \\
\text { government fédéral. Et jamais le retour du balancier } \\
\text { n'est venu. Le Québec est aujourd'hui considiré comme } \\
\text { une province parmi d'autres. Et portant le Canada ça } \\
\text { vient d'ici. }\end{array}$ & \\
\hline $\begin{array}{l}\text { CATEGORÍAS } \\
\text { FORMALES }\end{array}$ & $\begin{array}{l}\text { CATEGORÍAS DE LA REFERENCIA } \\
\text { NACIONALISTA: } \\
\text { Apelación a un origen (tiempo y espacio) }\end{array}$ & \\
\hline $\begin{array}{l}\text { Modalidad } \\
\text { de la expresión }\end{array}$ & Código: (73) & Palabras clave \\
\hline Epistémica & $\begin{array}{l}\text { C'est vrai que le parti québécois s'est fait doubler par } \\
\text { des gens qui veulent maintenant former un parti de gau- } \\
\text { che, et le parti libéral lui se dit plus à gauche parce qu'il } \\
\text { a fait élire une travailleuse sociale dans une élection } \\
\text { partielle. }\end{array}$ & $\begin{array}{l}\text { Disputes des } \\
\text { partis pour se } \\
\text { pencher à } \\
\text { gauche }\end{array}$ \\
\hline $\begin{array}{l}\text { CATEGORÍAS } \\
\text { FORMALES }\end{array}$ & $\begin{array}{l}\text { CATEGORÍAS DE LA REFERENCIA } \\
\text { NACIONALISTA: } \\
\text { Manifestaciones culturales de la diferencia }\end{array}$ & \\
\hline $\begin{array}{l}\text { Modalidad } \\
\text { de la expresión }\end{array}$ & Código: (74) & Palabras clave \\
\hline Epistémica & $\begin{array}{l}\text { Dans le domaine du militantisme presque tous les poè- } \\
\text { tes étaient carrément indépendantistes. Et l'on a jamais } \\
\text { vu au Québec un poète fédéraliste, un poète qui chantait } \\
\text { les vertus du fédéralisme, on n'en a jamais vu. Beau- } \\
\text { coup de poètes qui militaient pour le Québec libre et } \\
\text { dans ce sens là le mouvement nationaliste n'était pas } \\
\text { associé à une philosophie rétrograde, conservatrice ou } \\
\text { repliée sur elle-même comme le sont souvent les natio- } \\
\text { nalismes traditionnels comme on en voit en Europe. }\end{array}$ & $\begin{array}{l}\text { Les poètes qui } \\
\text { militaient pour } \\
\text { le Québec libre } \\
\text { n'é-taient pas } \\
\text { associés à u-ne } \\
\text { philosphie } \\
\text { rétrograde }\end{array}$ \\
\hline
\end{tabular}




\begin{tabular}{|c|c|c|}
\hline $\begin{array}{l}\text { CATEGORÍAS } \\
\text { FORMALES }\end{array}$ & $\begin{array}{l}\text { CATEGORÍAS DE LA REFERENCIA } \\
\text { NACIONALISTA: } \\
\text { Transcendencia de la categoría nacionalista }\end{array}$ & \\
\hline $\begin{array}{l}\text { Modalidad } \\
\text { de la expresión }\end{array}$ & Código: (75) & Palabras clave \\
\hline Epistémica & $\begin{array}{l}\text { Rire de la langue, oui. Quand on est classé comme des } \\
\text { Canadiens français à cause de la langue, mais il y a une si } \\
\text { grande partie de l'humour qui s'adresse à nous? Le } \\
\text { nationalisme se réclame de moins en moins de la langue. } \\
\text { Mais il y a eu un temps où la langue était un peu mieux } \\
\text { protégée. Ca s'effrite actuellement. C'est le gros problè- } \\
\text { me, la langue. Mais je ne pense pas qu'on puisse réduire } \\
\text { le nationalisme à ca. Je ne pense pas que ce soit le vœu le } \\
\text { plus cher que ce soit réduit à la langue. On pourrait dire } \\
\text { on vous donne une protection suffisante à la langue, } \\
\text { alors que ca va bien au-delà de ca, le nationalisme. }\end{array}$ & $\begin{array}{l}\text { Le nationalisme } \\
\text { se réclame de } \\
\text { moins en moins } \\
\text { de la langue. }\end{array}$ \\
\hline $\begin{array}{l}\text { CATEGORÍAS } \\
\text { FORMALES }\end{array}$ & REFERENCIAS AL GÉNERO HUMOR & \\
\hline $\begin{array}{l}\text { Modalidad } \\
\text { de la expresión }\end{array}$ & Código: (81) & Palabras clave \\
\hline Deóntica & $\begin{array}{l}\text { Oui, le rire, ou l'humour doit pas être forcément criti- } \\
\text { que.idem }\end{array}$ & \\
\hline $\begin{array}{l}\text { CATEGORÍAS } \\
\text { FORMALES }\end{array}$ & $\begin{array}{l}\text { CATEGORÍAS DE LA REFERENCIA } \\
\text { NACIONALISTA: } \\
\text { Tensiones (ruptura y continuidad) }\end{array}$ & \\
\hline $\begin{array}{l}\text { Modalidad } \\
\text { de la expresión }\end{array}$ & Código: (82) & Palabras clave \\
\hline Deóntica & $\begin{array}{l}\text { Moi je ne pense pas que le projet nationaliste puisse } \\
\text { répondre à toutes les aspirations. On se leurre dans un } \\
\text { sens et dans l'autre. Et puis de toute façon si on regarde } \\
\text { les réalités actuelles, c'est la mondialisation. On signe } \\
\text { avec le fédéral des accords sur l'éducation, l'immigra- } \\
\text { tion, et puis ca y est on dit on l'a notre souveraineté. La } \\
\text { reine, on la voit moins sur nos billets de banque. Mais } \\
\text { elle ne devrait même pas être là. Elle n'a rien à foutre là. } \\
\text { Je ne comprends pas ce qu'elle fait là. À partir du }\end{array}$ & $\begin{array}{l}\text { La reine, on la } \\
\text { voit moins sur } \\
\text { nos billets de } \\
\text { banque. Mais } \\
\text { elle ne devrait } \\
\text { même pas être } \\
\text { là. }\end{array}$ \\
\hline
\end{tabular}




\begin{tabular}{|c|c|c|}
\hline & $\begin{array}{l}\text { moment où la Constitution a été rapatriée, veut-tu me } \\
\text { dire What the fuck she is doing there? }\end{array}$ & \\
\hline $\begin{array}{l}\text { CATEGORÍAS } \\
\text { FORMALES }\end{array}$ & $\begin{array}{l}\text { CATEGORÍAS FORMALES CATEGORÍAS DE LA } \\
\text { REFERENCIA NACIONALISTA: } \\
\text { Apelación a un origen (tiempo y espacio) }\end{array}$ & \\
\hline $\begin{array}{l}\text { Modalidad } \\
\text { de la expresión }\end{array}$ & Código: (83) & Palabras clave \\
\hline Deóntica & $\begin{array}{l}\text { Il y a des choses que le libéral fédéral fait et qui sont inac- } \\
\text { ceptables, mais ils ne peuvent pas vraiment s'insurger par- } \\
\text { ce que ce serait presque aller du côté du parti québécois. }\end{array}$ & $\begin{array}{l}\text { Le libéraux } \\
\text { fédéraaux ne } \\
\text { peuvent pas } \\
\text { vraiment s'in- } \\
\text { surger }\end{array}$ \\
\hline $\begin{array}{l}\text { CATEGORÍAS } \\
\text { FORMALES }\end{array}$ & $\begin{array}{l}\text { CATEGORÍAS DE LA REFERENCIA } \\
\text { NACIONALISTA: } \\
\text { Manifestaciones culturales de la diferencia }\end{array}$ & \\
\hline $\begin{array}{l}\text { Modalidad } \\
\text { de la expresión }\end{array}$ & Código: (84) & Palabras clave \\
\hline Deóntica & $\begin{array}{l}\text { À un certain moment il y a une limite à ne pas franchir: } \\
\text { Parler de la disgrâce de quelqu'un, ou d'un handicap quel- } \\
\text { conque (L. Bouchard) Si on trouve ça horrible, on devrait } \\
\text { aussi dénoncer tous les caricaturistes qui ont dessiné Jean } \\
\text { Chrétien en mettant l'accent sur sa bouche croche ou quel- } \\
\text { que chose comme ça. Les Québécois francophones qui sor- } \\
\text { tent du secondaire parlent peu ou pas l'anglais. Mais parce } \\
\text { qu'on a obligé les anglophones à étudier le français, ...Pas } \\
\text { pour longtemps. C'est justement pour cette raison qu'il } \\
\text { faut leur lever le chapeau. Les anglophones qui sortent de } \\
\text { l'école secondaire parlent très bien le français. }\end{array}$ & $\begin{array}{l}\text { Il faut leur } \\
\text { lever le } \\
\text { chapeau: les } \\
\text { an-glophones } \\
\text { qui sortent de } \\
\text { l'école secon- } \\
\text { daire parlent } \\
\text { très bien le } \\
\text { français. }\end{array}$ \\
\hline $\begin{array}{l}\text { CATEGORÍAS } \\
\text { FORMALES }\end{array}$ & $\begin{array}{l}\text { CATEGORÍAS DE LA REFERENCIA } \\
\text { NACIONALISTA: } \\
\text { Transcendencia de la categoría nacionalista }\end{array}$ & \\
\hline $\begin{array}{l}\text { Modalidad } \\
\text { de la expresión }\end{array}$ & Código: (85) & Palabras clave \\
\hline Deóntica & $\begin{array}{l}\text { Moi je ne pense pas que le projet nationaliste puisse } \\
\text { répondre à toutes les aspirations. On se leurre dans un }\end{array}$ & $\begin{array}{l}\text { Le projet na- } \\
\text { tionaliste ne }\end{array}$ \\
\hline
\end{tabular}




\begin{tabular}{|c|c|c|}
\hline & $\begin{array}{l}\text { sens et dans l'autre. Et puis de toute façon si on regarde } \\
\text { les réalités actuelles, c'est la mondialisation. On signe } \\
\text { avec le fédéral des accords sur l'éducation, l'immigra- } \\
\text { tion, et puis ca y est on dit on l'a notre souveraineté. }\end{array}$ & $\begin{array}{l}\text { peut plus ré- } \\
\text { pondre à tou- } \\
\text { tes les } \\
\text { aspirations. }\end{array}$ \\
\hline $\begin{array}{l}\text { CATEGORÍAS } \\
\text { FORMALES }\end{array}$ & $\begin{array}{l}\text { CATEGORÍAS FORMALES } \\
\text { REFERENCIAS AL GÉNERO HUMOR }\end{array}$ & \\
\hline $\begin{array}{l}\text { Modalidad } \\
\text { de la expresión }\end{array}$ & Código: (91) & Palabras clave \\
\hline \multicolumn{3}{|l|}{ Existencial } \\
\hline $\begin{array}{l}\text { CATEGORÍAS } \\
\text { FORMALES }\end{array}$ & $\begin{array}{l}\text { CATEGORÍAS DE LA REFERENCIA } \\
\text { NACIONALISTA: } \\
\text { Tensiones (ruptura y continuidad) }\end{array}$ & \\
\hline $\begin{array}{l}\text { Modalidad } \\
\text { de la expresión }\end{array}$ & Código: (92) & Palabras clave \\
\hline Existencial & $\begin{array}{l}\text { Le gouvernement fédéral a réussi à renforcer, à centrali- } \\
\text { ser son pouvoir en créant une espèce de solidarité artifi- } \\
\text { cielle entre les provinces. Il faut dire qu'il y a plus de } \\
\text { différence entre les gens qui habitent Terre neuve et les } \\
\text { gens de la Colombie britannique qu'entre les Québécois } \\
\text { puis les Ontariens. Mais diviser pour régner? la stratégie } \\
\text { d'Ottawa a toujours été de liguer les autres provinces } \\
\text { contre le Québéc, parce que Québec représente la mena- } \\
\text { ce sécessionniste. Je pense que pour faire une révolu- } \\
\text { tion, il faut avoir mangé tellement de merde, avoir telle- } \\
\text { ment souffert que l' on est prêt à tous les excès pour } \\
\text { atteindre le but recherché. Quand on est comme nous, } \\
\text { gatés, il ne nous manque rien, c'est évident que notre } \\
\text { idiologie, nos aspirations politiques, en tant que natio- } \\
\text { nalistes, ne sont pas satisfaits, c'est evident. Mais on ne } \\
\text { manque de rien. On crêve pas de faim, on a des maisons } \\
\text { chaudes pour se loger, on peut s'habiller, on a tout ce } \\
\text { qu'il faut. Alors on n'est pas motivé. On a des voitures } \\
\text { qui polluent, on a tout ce qu'il faut,. On n'est pas suffi- } \\
\text { samment motivé pour faire la révolution. C'est pas la } \\
\text { révolution francaise là ou on a coupé la tête de Louis } \\
\text { XVI parce que les gens crevaient de faim, parce que les } \\
\text { gens étaient au désespoir, parce que les gens étaient au } \\
\text { désespoir, vivaient dans la misêre noire, quand les gens } \\
\text { en ont franchement ras le bol, quand ils ont mangé suffi- } \\
\text { samment de merde pour dire ca suffit. Nous on est gatés }\end{array}$ & $\begin{array}{l}\text { La stratégie } \\
\text { d'Ottawa a } \\
\text { toujours été de } \\
\text { liguer les } \\
\text { autres provin- } \\
\text { ces contre le } \\
\text { Québéc ,parce } \\
\text { que Québec } \\
\text { représente la } \\
\text { menace séce- } \\
\text { ssionniste Mais } \\
\text { on n'est pas } \\
\text { suffisam-ment } \\
\text { motivé pour } \\
\text { faire la } \\
\text { révolution. }\end{array}$ \\
\hline
\end{tabular}




\begin{tabular}{|c|c|c|}
\hline & $\begin{array}{l}\text { ici. Alors nos aspirations sont très légitimes, mais quand } \\
\text { tu as ta bière, ton journal que tu es au chaud dans ta mai- } \\
\text { son, pourquoi tu ferais la révolution pour avoir un Qué- } \\
\text { bec libre. C'est ça. Les revolutions, ca se fait dans le } \\
\text { sang, ca ne se fait pas en démocratie. La révolution tran- } \\
\text { quille a de toutes façons, nous les Québecois on est } \\
\text { tellement nono(sens de mou), onest tellement asservis, } \\
\text { on est tellement à genoux devant tout le monde que le } \\
\text { jour oú on va faire sauter des bombes.. Quand on l'a } \\
\text { fait, Ottawa s'est empressé de faire la loi des mesures de } \\
\text { guerre pour nous écraser. Alors on reste bien pipères. }\end{array}$ & \\
\hline $\begin{array}{l}\text { CATEGORÍAS } \\
\text { FORMALES }\end{array}$ & $\begin{array}{l}\text { CATEGORÍAS DE LA REFERENCIA } \\
\text { NACIONALISTA: } \\
\text { Apelación a un origen (tiempo y espacio) }\end{array}$ & \\
\hline $\begin{array}{l}\text { Modalidad } \\
\text { de la expresión }\end{array}$ & Código: (93) & Palabras clave \\
\hline \multicolumn{3}{|l|}{ Existencial } \\
\hline $\begin{array}{l}\text { CATEGORÍAS } \\
\text { FORMALES }\end{array}$ & $\begin{array}{l}\text { CATEGORÍAS DE LA REFERENCIA } \\
\text { NACIONALISTA: } \\
\text { Manifestaciones culturales de la diferencia }\end{array}$ & \\
\hline $\begin{array}{l}\text { Modalidad } \\
\text { de la expresión }\end{array}$ & Código: (94) & Palabras clave \\
\hline Existencial & $\begin{array}{l}\text { Dans le cas de Jean Chrétien, avoir la bouche croche, } \\
\text { c'est exactement comme le contrepoids de la jambe arti- } \\
\text { ficielle de Lucien Bouchard. C'est une infirmité, c'est le } \\
\text { résultat d'une maladie, de la même manière que Chré- } \\
\text { tien a eu une maladie qui a donné une paralysie facia- } \\
\text { le... Et ça a été exploité par d'autres partis politiques, il } \\
\text { y a eu un tollé de protestations. }\end{array}$ & $\begin{array}{l}\text { Il y a eu un } \\
\text { tollé de } \\
\text { protestations. }\end{array}$ \\
\hline $\begin{array}{l}\text { CATEGORÍAS } \\
\text { FORMALES }\end{array}$ & $\begin{array}{l}\text { CATEGORÍAS FORMALES CATEGORÍAS } \\
\text { DE LA REFERENCIA NACIONALISTA: } \\
\text { Transcendencia de la categoría nacionalista }\end{array}$ & \\
\hline $\begin{array}{l}\text { Modalidad } \\
\text { de la expresión }\end{array}$ & Código: (95) & Palabras clave \\
\hline Existencial & & \\
\hline
\end{tabular}




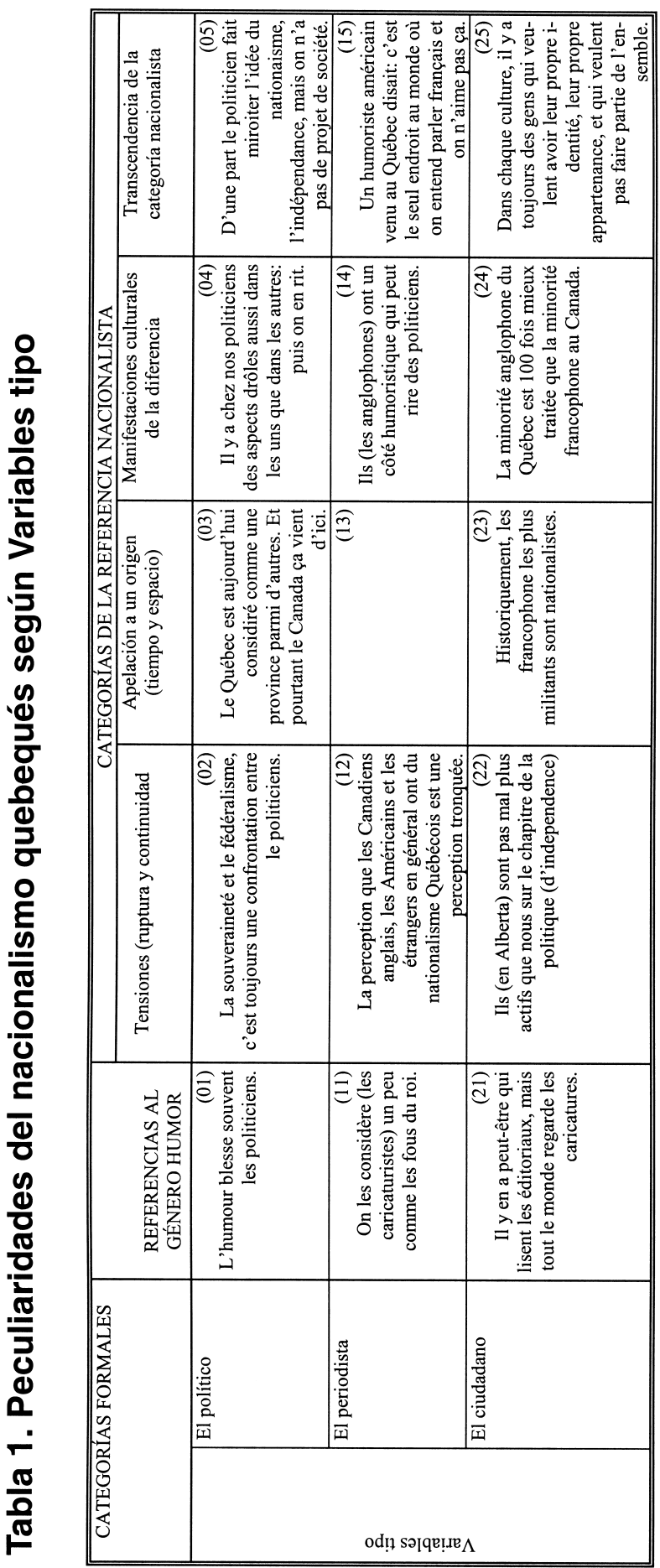




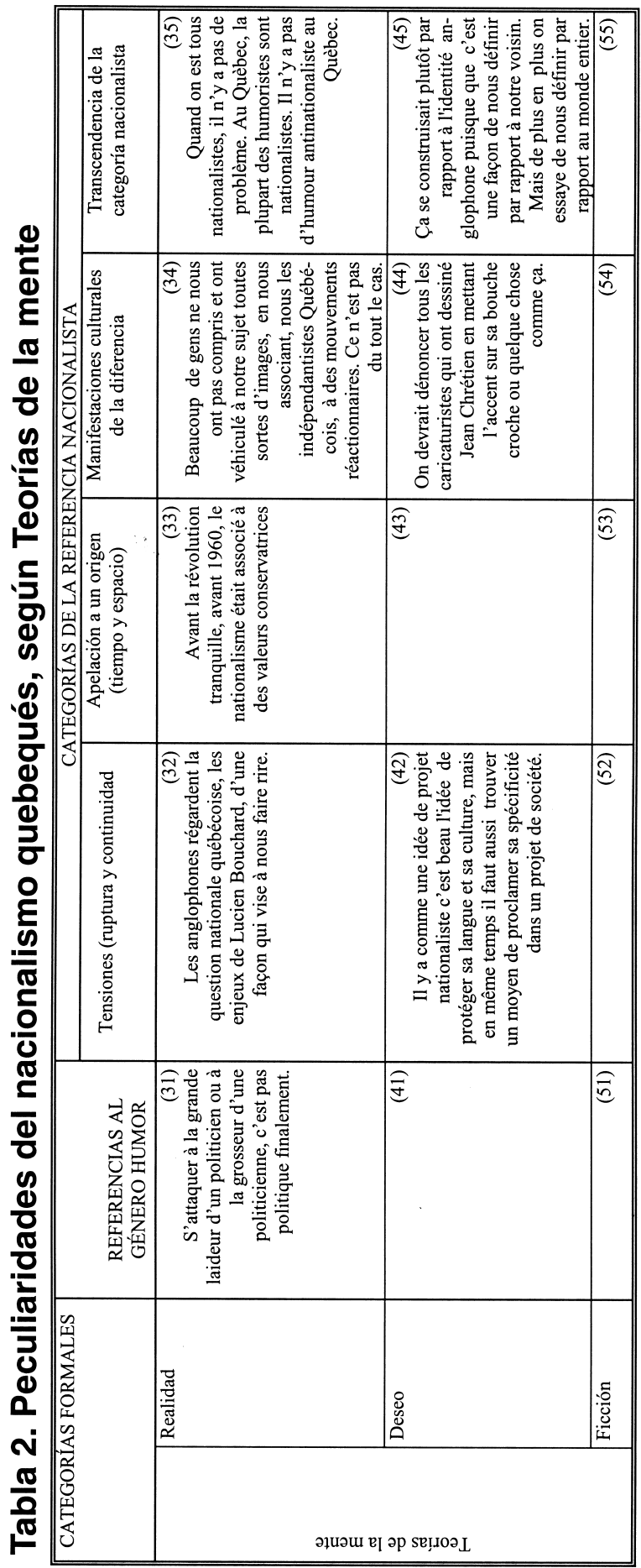




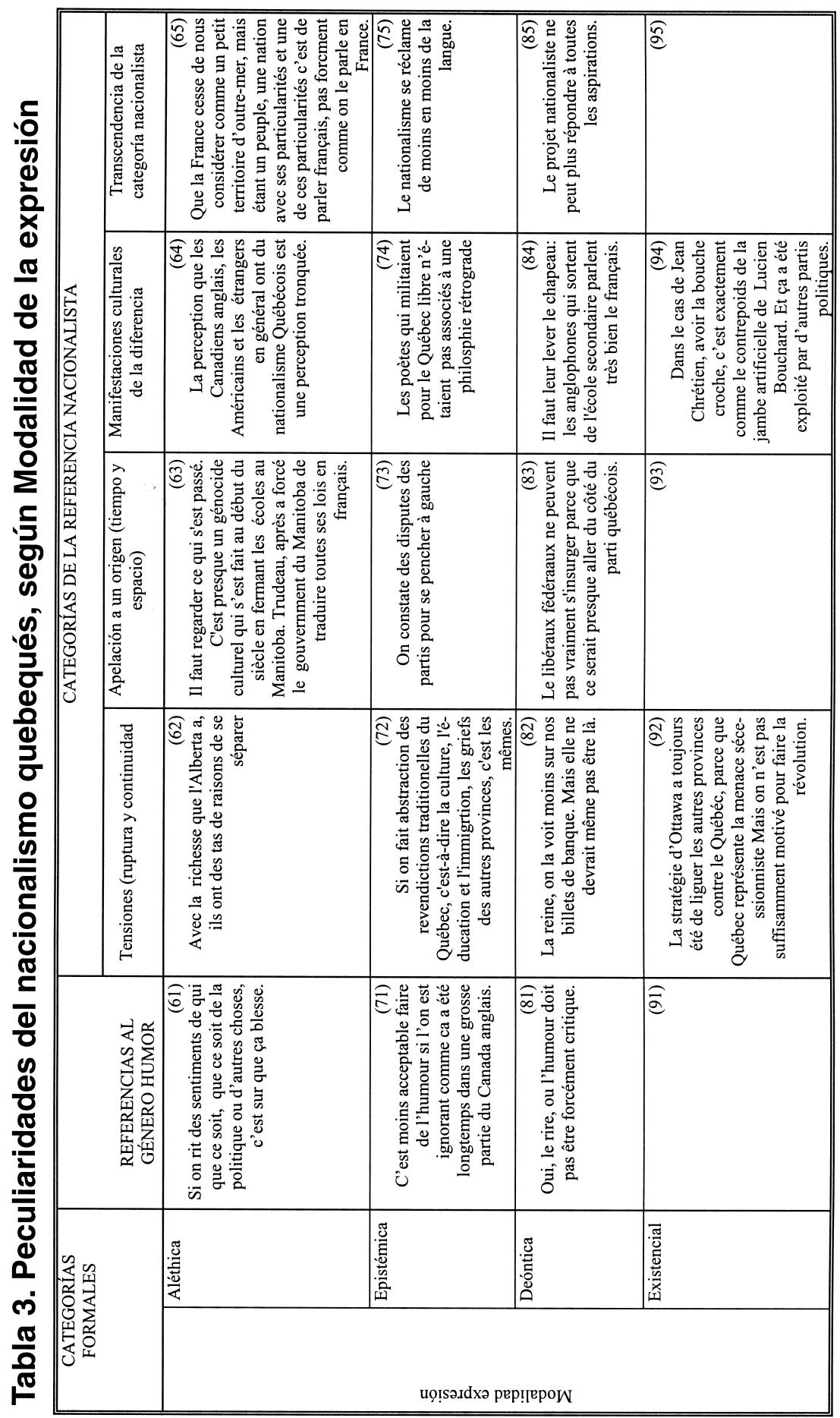




\section{CONCLUSIONES}

En el planteamiento de esta investigación se ha reiterado que nuestro objetivo era abordar el estudio de la representación colectiva del nacionalismo con el fin de comprobar cómo las identidades colectivas de una comunidad pueden ser mediadoras de los procesos cognitivos con que se interpretan los flujos mediáticos. Que hemos elegido un nacionalismo como el de Québec porque supuestamente es diferente de aquellos otros fuertemente contaminados por las tensiones cosmogónicas excluyentes que derivan de la violencia terrorista, pero que, sin embargo, no renuncia a aspiraciones de independencia política. Y que la elección, metodológicamente estratégica, de estudiar el nacionalismo de Québec, permite, por otra parte, proseguir con estudios posteriores susceptibles de abordar comparaciones interculturales.

Nuestro método y nuestro utillaje metodológico nos han conducido después a plantearnos un diseño cuasi experimental consistente en reunir a nacionalistas quebequeses para debatir en grupo sobre el género mediático del humor y de la política. Y en este sentido, lo primero que experimentalmente pudo comprobarse fue que a medida que se proyectaban los estímulos para la discusión (las caricaturas en la primera fase de las sesiones de discusión), se producía la hilaridad en todos los grupos, y que en todas las ocasiones se instauró la complicidad entre los participantes entrando en un vínculo grupal que se manifestaba mediante gestos y risas aprobatorias para expresar la perfecta comprensión de las caricaturas, dispuestos entonces a poner en común el capital cognitivo de su «auto-referencia» nacionalista. Pero ¿cuál es este capital mediador?

\section{Variables y valores tipo característicos del nacionalismo quebequés}

La primera hipótesis que cabía rastrear en las transcripciones del discurso grupal tiene que ver con esta pregunta: ¿se manifiestan en la expresión del discurso variables y valores tipo, características del nacionalismo, en la identificación y apreciación del género periodístico del humor en la política, que distingan al político, al periodista y al ciudadano? ¿Cómo?

Tanto de la lectura de los segmentos de discurso consignados en las categorías 01,11, y 21 , como de la lectura de la Tabla 1 , se desprende que el género del humor referido a la política es bien aceptado, que los ridiculizados son en todo caso los políticos, si bien a veces resultan ridículos; que aunque los caricaturistas merecen cierta indulgencia, no deben sobrepasar ciertos límites (en especial los referidos al maltrato a políticos nacionalistas); y que, finalmente, los ciudadanos aprecian este género.

Pero las peculiaridades más relevantes del discurso nacionalista quebequés son las consignadas bajo los rubros «Tensiones (ruptura y continuidad)», «Apelación a un origen (tiempo y espacio)», «Manifestaciones culturales de la diferencia», y «Transcendencia de la categoría nacionalista», los cuales permiten apreciar expresiones más favorables si son referidas al ciudadano, que al periodista (humorista) o al político; así, el ciudadano aparece siempre como sujeto que 
le reclama al periodista visiones más acertadas de su realidad identitaria y cultural, y al político un proyecto de sociedad; pero sobre todo el ciudadano de Québec es el que aparece como sujeto de la actuación nacionalista tanto para marcar la ruptura frente a las metrópolis históricas (Reino Unido y Francia) como frente a las metrópolis americanas (Otawa incluída); el que aparece igualmente como sujeto que reclama una identidad vinculada al origen de Canadá, pero también como sujeto en minoría (un quebequés por cada cuatro canadienses) que, menospreciado por sus vecinos y retrocediendo en su afirmación lingüística y cultural, reivindica una identidad diferenciada frente al mundo...

\section{Teorías de la mente que instauran el acuerdo en el discurso nacionalista}

Visto cómo el ciudadano de Québec llega a reclamarle al periodista y al político su razón a la diferencia, ¿cuáles son las «teorías de la mente» en función de las cuales el «acuerdo» que se instaura en el discurso del grupo nacionalista otorga al género del humor un rango de realidad, de deseo o de simulación?; o ¿cuáles son las «teorías de la mente» en función de las cuales se le supone realidad, deseo o ficción a las dimensiones vinculadas a una afirmación nacionalista propia, como son las «Tensiones (ruptura y continuidad)», «Apelación a un origen (tiempo y espacio)», «Manifestaciones culturales de la diferencia», y «Transcendencia de la categoría nacionalista»?; o, en último término, ¿cuáles son las creencias y expectativas comprometidas al hilo de la discusión?

Vistas las secuencias del discurso y las «palabras clave» correspondientes a las categorías 31, 41 y 51, se comprueba que el género mediático del humor y la política no merece ningún comentario en las discusiones que pueda ser remitido al deseo ni a la ficción, ya que supuestamente este género aborda sólo dimensiones de la realidad, pero una realidad menor, sin trascendencia política. Y vistas las secuencias del discurso y las «palabras clave» correspondientes a las categorías cuya referencia remite al nacionalismo desde los supuestos alternativos de la apelación a lo que ocurre (realidad), a lo que se aspira (deseo), o a lo que se simula (ficción), se comprueba que no aparecen comentarios en las discusiones que puedan ser remitidos a la ficción; que los comentarios cuya apelación es el deseo pueden orientarse a referencias sobre las «Tensiones (ruptura y contuidad)», sobre «Manifestaciones culturales de la diferencia», o sobre «Transcendencia de la categoría nacionalista», pero no sobre «Apelación a un origen (tiempo y espacio)». Igualmente puede apreciarse que la apelación a la realidad, hablando a propósito de las «Tensiones (ruptura y continuidad)», se centra prioritariamente en aquellas tensiones marcadas por la relación con los anglófonos canadienses, si bien desde una clave peculiar, como es aquello que merece o no la risa; mientras que la apelación al deseo, hablando también a propósito de las «Tensiones (ruptura y continuidad)», se centra en la expresión de una carencia: la existencia de un proyecto de sociedad tras la buena idea nacionalista de reivindicar la protección de la lengua y la cultura.

Por otra parte, la apelación a la realidad, hablando a propósito de la «Apelación a un origen (tiempo y espacio)», gira en torno al cambio histórico de la 
«revolución tranquila» (años '60) a partir de la cual el nacionalismo quebequés adquiere un rumbo progresista abandonando valores conservadores. Igualmente la apelación a la realidad, hablando a propósito de las «Manifestaciones culturales de la diferencia», sirve para reivindicar otra imagen de los independentistas quebequeses que no sea la tradicional de asociarlos a movimientos reaccionarios, mientras que hablando a propósito de las «Manifestaciones culturales de la diferencia», la apelación al deseo se centra en el respeto a los líderes nacionalistas.

Finalmente, las expresiones del discurso que remiten a la «Transcendencia de la categoría nacionalista», centran su apelación a la realidad reivindicando precisamente la identidad nacionalista de Québec tanto frente a Francia, como frente a los anglófonos canadienses y afirmando que, incluso el humor, es nacionalista en Québec, y centran su apelación al deseo, marcando una identidad que aspira a construir la diferencia frente a los vecinos anglófonos, pero sobre todo capaz de definirse como tal frente al mundo entero.

\section{Modalidades de la expresión en el discurso nacionalista}

La tercera gran categoría de análisis tenía que ver con las modalidades de la expresión. Así, el universo de referencia (con mayor o menor riqueza de temas, personajes, acciones, etc.) puede ser planteado en el discurso desde muchas formas de modalidad, entre ellas la aléthica (es decir, lo necesario, lo posible, lo contingente o lo imposible), la epistémica (es decir, lo verificado, lo probable, lo aún no decidido, lo falsado, etc.), la deóntica (es decir, lo obligatorio, lo permitido, lo indiferente, lo prohibido, etc.) o la existencial (o sea, lo universal, lo existente, lo indeterminado, o lo vacío, etc.).

Tanto de la lectura de los segmentos de discurso consignados en las categorías $61,71,81$ y 91 , como de la lectura de la Tabla 3 , se desprende que el género del humor referido a la política es reconocido como algo que con toda seguridad puede herir cuando ataca los sentimientos de cualquiera, que no es aceptable el humor si no se está bien informado, y que no siempre el humor mediático tiene que ser forzosamente crítico.

Si se toman en cuenta las modalidades de la expresión cuando ésta remite a la referencia nacionalista en torno a las «Tensiones (ruptura y continuidad)», se comprueba que, puestos a platearse la separación de Canadá, hay indicios de la posibilidad (modalidad aléthica) de que la desvinculación del país comience por Alberta, más poderosos económicamente; que, abstracción hecha (modalidad epistémica) de las reivindicaciones tradicionales de Québec en lo que concierne a la cultura, a la educación y a la inmigración, todas las provincias en realidad se disputan lo mismo, o pueden plantear las mismas quejas; que puestos a expresar categóricamente algo que no debiera ocurrir (modalidad deóntica), esto es que la Reina de Inglaterra aparezca en los billetes de la moneda; y finalmente, puestos a consignar matices (modalidad existencial) de lo que ocurre en relación a las tensiones entre ruptura y continuidad, frente a la estrategia de Otawa por unir al resto de las provincias contra Québec por su amenaza secesionista, hay que concluir que el nacionalismo quebequés no está motivado para hacer ninguna revolución. 
$\mathrm{Si}$, por otra parte, se toman en cuenta las modalidades de la expresión cuando ésta remite a la referencia nacionalista en torno a la «Apelación a un origen (tiempo y espacio)», se comprueba que, puestos a citar historias pasadas, es necesario (modalidad aléthica) concluir que los líderes políticos nacionalistas de Québec no lo han hecho tan mal, pues han defendido causas justas frente a atropellos políticos de la gente; que puestos a constatar (modalidad espistémica) historias pasadas, todas las luchas entre partidos nacionalistas quebequeses han consistido en disputarse el giro hacia la izquierda política, y no, como es la imagen tradicionalmente arrastrada, hacia la derecha conservadora; que puestos a expresar que es lo que históricamente no le está permitido (modalidad deóntica) a algún partido nacionalista, es pisarle el terreno a otro partido en lo que a lucha por la soberanía se refiere.

Reparando en las modalidades de la expresión cuando ésta se remite a la referencia nacionalista de «Manifestaciones culturales de la diferencia» se comprueba que, puestos a valorar la contingencia (modalidad aléthica) de la percepción que los ingleses canadienses, los americanos y los extranjeros tienen de los rasgos nacionalistas de Québec, esta percepción es siempre equivocada; que, decididos a hacer constatar (modalidad epistémica) una particularidad asociada a los poetas nacionalistas de Québec, nunca éstos han mostrado una filosofía retrógrada; que puestos a encomiar alguna obligación (modalidad deóntica) referida a las manifestaciones culturales de la diferencia respecto a sus vecinos los canadienses ingleses, ésta es reconocer que los canadienses ingleses salen de secundaria hablando bien el francés, lo que no es el caso para los canadienses franceses respecto al inglés; que finalmente, en caso de tener que consignar alguna categoría general frente a casos particulares de alguna diferencia (modalidad existencial), las expresiones del discurso nacionalista registrado citan la protesta generalizada frente a la explotación que otros partidos no nacionalistas han hecho de las desgraciadas secuelas de enfermedades sufridas por determinados líderes nacionalistas, como Lucien Bouchard o Jean Chrétien.

En fin, fijando la atención en las modalidades de la expresión cuando ésta se remite a la «Transcendencia de la categoría nacionalista», puede comprobarse que si algo se valora como absolutamente necesario (modalidad aléthica) es que Francia deje de considerar a Québec como una provincia de ultramar, sino que la considere una nación, un pueblo con todas sus particularidades, entre ellas hablar francés, aunque diferente del hablado en Francia; que al fin y al cabo, considerando causas y efectos (modalidad epistémica) el nacionalismo se reclama cada vez menos ligado a la lengua; y que finalmente, puestos a expresar algún matiz relacionado con lo obligatorio, o lo permitido, o lo indiferente, o lo prohibido, etc. (modalidad deóntica) hay que decir que el proyecto nacionalista no es lo que puede colmar todas las aspiraciones.

No quiero terminar esta exposición sin añadir un comentario final que puede resumir toda la riqueza de esta experiencia científica empeñada en estudiar, en pleno proceso de globalización, cómo las identidades colectivas (como en este caso el nacionalismo de Québec) pueden hacer llegar a hacer compatibles nacionalismo y universalidad. Es obvio que globalización y nacionalismo parecen nociones contrapuestas hasta el punto de que la defensa de una implicaría la 
negación de la otra, y sin embargo es la práctica de la comunicación la que las hace compatibles e incluso complementarias. En este sentido, hemos podido constatar que los esquemas cognitivos disponibles en el nacionalismo de Québec hacen posible a la vez la expresión de la particularidad y la expresión de la globalidad, habida cuenta del supuesto de que este nacionalismo, como todo nacionalismo, hunde sus raíces en la historia de las comunidades locales (tensión centrípeta), mientras que la globalización desborda cualquier localismo apuntando hacia afuera (tensión centrífuga), tratando de afirmarse universalmente, que es quizá la particularidad más relevante del nacionalismo en Québec. Espero y deseo ya poder comparar estos resultados estudiando con las mismas herramientas otros nacionalismos.

\section{REFERENCIAS BIBLIOGRÁFICAS}

Piñuel J. L. y Gaitán J. A., (1995), Metodología General. Conocimiento científico e investigación en la Comunicación social. Ed. Síntesis. Madrid

PIÑUEl J. Luis. (1997), Teoría de la Comunicación y gestión de las organizaciones. Ed. Síntesis. Madrid

Piñuel, J. Luis (1986), El terorismo en la Transición española. Ed. Fundamentos. Madrid.

PIÑUEL J. Luis et alt. (1987), El consumo cultural. Ed. Fundamentos. Madrid.

PIÑUEL J. Luis (1993), Cultura política y TV en la transición en Chile. Ed. C.E.D.E.A.L. Madrid.

CAstells, Manuel (1998), La sociedad de la Información. Ed. Alianza Universidad. Madrid.

PiÑUel J. L. y G-Lomas, J. I. (2001), «Autopoiesis y Comunicación». 3er. Congreso Internacional de Sociocibernética. León. (México)

Martín SERrano, M. El alt., (1981), Epistemología de la comunicación y análisis de la referencia. Ed. Visor. Madrid.

MARTín SERRANO, M. (1989), La producción social de comunicación. Ed. Alianza Universidad. Madrid.

PiñUel RAigada, J. Luis. (1989), La expresión. Una introducción a la filosofía de la Comunicación. Ed. Visor. Madrid.

IbAÑEZ, Jesús (1986), Más allá de la sociología. Ed. Siglo XXI. Madrid.

GAITÁN J. A. y PIÑUEL J. L., (1997), Técnicas de investigación social. Elaboración y registro de datos. Ed. Síntesis. Madrid.

Canales y Peinado (1994), «Grupos de discusión» en J. Delgado et al. Métodos y Técnicas cualitativas de investigación en Ciencias Sociales. Ed. Sintesis. Madrid.

LIPPMAN, W. (1922), Public opinion. N.York, Macmillan.

George, A. L. (1959), Propaganda Analysis: A study of inferences made from Nazi propaganda in World War II. Evanston, IL, Row, Peterson.

Pool, I. de S. (1959), Trend in Content Analysis. Urbana, Univ. of Illinois. Illinois.

LASSWEll, H. (1965), «Why be quantitative?». en H. Lasswell, H. y N. Leites (comps.): Language of Politics. Cambridge, MIT Press.

Holsti, O. R. (1969), Content Analysis for the Social Sciences and Humanities. MA. Reading Addison-Wesley.

BOUCHARD, Gérard (2001), Genèse des nations et cultures du nouveau monde. Ed. Boreal Montreal. 


\section{RESUMEN}

El estudio de la representación del nacionalismo, justamente en este momento histórico, cuando el proceso de globalización se extiende, constituye un reto científico para comprender cómo la mediación llega a ser mediatizada a su al rededor por la historia local de comunidades históricas. Yo he estudiado en distintos momentos problemas de la comunicación relacionados con la construcción de identidades colectivas, y he utilizado frecuentemente la metodología del análisis de contenido para estudiar los flujos comunicativos de los media. Ahora estoy interesado por el estudio de los discursos que se producen en los grupos de discusión, los cuales se enfrentan al debate de la actualidad política en los periódicos. Pero para llegar a comprender bien el análisis que procede de los relatos de los medias, y de lo que es aportado por los esquemas cognitivos previos donde un grupo dispone la construcción del sentido del discurso, hay que elegir un objeto de estudio que permita:

- Delimitar el universo de referencia de los productos mediáticos susceptibles de poner en marcha la discusión.

- Delimitar el universo de referencia de esquemas cognitivos en los cuales cada grupo tiene la posibilidad de construir el sentido del discurso.

- Delimitar un universo de referencia susceptible de facilitar tanto la elección de los grupos como la comparación intercultural.

He descubierto que el objeto de estudio que hace posible todo esto es el NACIONALISMO, puesto que se trata de un universo de referencias a menudo presente en el flujo mediático, y sobre todo, el universo de referencia del nacionalismo, que encierra siempre un capital cognitivo muy rico de esquemas cognitivos. En este punto, mi investigación comienza por el estudio de la representación del nacionalismo en el discurso de pequeños grupos que abordan en su conversación el debate sobre noticias mediáticas de actualidad política. Y además, el nacionalismo, representa un universo de referencias susceptible de facilitar la comparación intercultural. Para mejor iniciar esta comparación, he decido comenzar por la representación del nacionalismo en Canadá, puesto que en él, hay un proceso de apropiación racional en diferentes etapas, un movimiento de independencia política más racional y democrático que el nacionalismo vasco -más violento y arcaico- de nuestro país.

\section{RÉSUMÉ}

L'étude de la représentation du nationalisme, justement au moment historique où le processus de globalisation s'étend partout, constitue un défi scientifique pour comprendre comment la Médiation communicationnelle (Piñuel, 1995, Piñuel, 1997) devient médiatisée, à son tour, par l' histoire locale des communautés historiques. J'ai étudié à plusieurs reprises des problèmes de la communication rapportés à la construction des identités collectives (Piñuel, 1986, Piñuel 1987, Piñuel 1993, Piñuel y Gaitán 
1995, etc.), et j’ ai utilisé fréquement la méthodologie de l'analyse de contenu pour étudier le flux communicatif des Médias. Maintenant je suis intéressé dans l'étude du discours qui est produit par des groupes de discussion lorsqu'ils se heurtent à débattre l'actualité politique des journaux; mais pour arriver à bien déceler par l'analyse ce qui est provenant des récits des Médias et ce qui est apporté par les schémas cognitifs préalables dont un groupe dispose en construisant le sens du discours, je dois choisir un objet d'étude permettant:

- Cerner l' univers de référence des produits médiatiques susceptibles de déclencher la discussión

- Cerner l'univers de référence des schémas cognitifs dont chaque groupe dispose pour construire le sens du discours

- Cerner un univers de réference susceptible de faciliter autant les choix des groupes, que la comparaison interculturelle.

J'ai trouvé que l'objet d'étude qui permet tout cela est le NATIONALISME, puisqu'il s'agit d'un univers de référence souvent présent dans le flux médiatique, et, surtout, l'univers de référence du NATIONALISME renferme toujours un capital cognitif tres riche de schémas collectifs. Dans ce but, ma recherche commence par l'étude de la représentation du nationalisme dans le discours de petits groupes lorsqu' ils abordent la conversation et les débâts sur des nouvelles médiatiques de l'actualité politique. En plus, le NATIONALISME répresente un univers de référence susceptible de faciliter la comparaison interculturelle, et pour mieux entamer cette comparaison, j'ai choisi de commencer par l'étude de la représentation du nationalisme au Canada, étant donné qu'il y a un processus d'appropiation nationale visant à plusieures réprises un mouvement d'independance politique beaucoup plus rationnel et démocratique que le nationalisme basque de chez nous, -plus violent er archaïque-. 